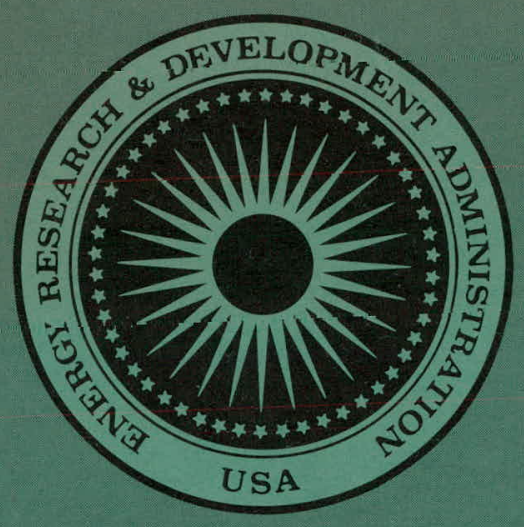

BERC/RI-76/16

TOTAL LUMINESCENCE CONTOUR SPECTRA

OF SIX TOPPED CRUDE OILS

By

Baird-Atomic, Inc. for ERDA

Under Order No. BE-76-P-1221

Date Published-November 1976

Bartlesville Energy Research Center

Energy Research and Development Administration

Bartlesville, Oklahoma 


\section{DISCLAIMER}

This report was prepared as an account of work sponsored by an agency of the United States Government. Neither the United States Government nor any agency Thereof, nor any of their employees, makes any warranty, express or implied, or assumes any legal liability or responsibility for the accuracy, completeness, or usefulness of any information, apparatus, product, or process disclosed, or represents that its use would not infringe privately owned rights. Reference herein to any specific commercial product, process, or service by trade name, trademark, manufacturer, or otherwise does not necessarily constitute or imply its endorsement, recommendation, or favoring by the United States Government or any agency thereof. The views and opinions of authors expressed herein do not necessarily state or reflect those of the United States Government or any agency thereof. 


\section{DISCLAIMER}

Portions of this document may be illegible in electronic image products. Images are produced from the best available original document. 


\section{NOTICE}

This report was prepared as an account of work sponsored by the United States Government. Neither the United States nor the United States Energy Research and Development Administration, nor any of their employees, nor any of their contractors, subcontractors, or their employees, makes any warranty, express or implied, or assumes any legal liability or responsibility for the accuracy, completeness or usefulness of any information, apparatus, product or process disclosed, or represents that its use would not infringe privately owned rights.

This report has been reproduced directly from the best available copy.

Available from the National Technical Information Service, U.S. Department of Commerce, Springfield, Virginia 22161.

NATIONAL TECHNICAL INFUHMATION GERVICH PAPFR SOPY PRICES EFFECTIVE JAN. 1, 1976

$\begin{array}{cccccccccccc}\begin{array}{c}\text { Page } \\ \text { range }\end{array} & \begin{array}{c}\text { Domestic } \\ \text { price }\end{array} & \begin{array}{c}\text { Page } \\ \text { range }\end{array} & \begin{array}{c}\text { Domestic } \\ \text { price }\end{array} & \begin{array}{c}\text { Page } \\ \text { range }\end{array} & \begin{array}{c}\text { Domestic } \\ \text { price }\end{array} & \begin{array}{c}\text { Page } \\ \text { range }\end{array} & \begin{array}{c}\text { Domestic } \\ \text { price }\end{array} & \begin{array}{c}\text { Page } \\ \text { range }\end{array} & \begin{array}{c}\text { Domestic } \\ \text { price }\end{array} & \begin{array}{c}\text { Page } \\ \text { range }\end{array} & \begin{array}{c}\text { Domestic } \\ \text { price }\end{array} \\ 001.025 & \$ 3.50 & 126-150 & \$ 6.00 & 251-275 & \$ 9.00 & 376-400 & \$ 10.75 & 501-525 & \$ 12.75 & 701-800 & \$ 18.75 \\ 026-050 & \$ 4.00 & 151-175 & \$ 6.75 & 276-300 & \$ 9.25 & 401.425 & \$ 11.00 & 526-550 & \$ 13.00 & 801-900 & \$ 21.25 \\ 051.075 & \$ 4.50 & 176-200 & \$ 7.50 & 301-325 & \$ 9.75 & 426-450 & \$ 11.75 & 551-575 & \$ 13.50 & 901-1000 & \$ 23.75 \\ 076-100 & \$ 5.00 & 201-225 & \$ 7.75 & 326-350 & \$ 10.00 & 451.475 & \$ 12.00 & 576-600 & \$ 13.75 & 1001-1100 & \$ 28.25 \\ 101-125 & \$ 5.50 & 226-250 & \$ 8.00 & 351.375 & \$ 10.50 & 476-500 & \$ 12.50 & 601-700 & \$ 16.25 & 1101-1200 & \$ 32.75\end{array}$

For additional pages, add $\$ 4.50$ for each beginning 100 pages. Add $\$ 2.50$ per copy for foreign price.

Microfiche $\$ 3.00$ (domestic) $\$ 4.50$ (foreign). 
BERC/RI-76/16

Distribution Category UC-92b

\title{
TOTAL LUMINESCENCE CONTOUR SPECTRA OF SIX TOPPED CRUDE OILS
}

\author{
By \\ B. R. Chisholm, H. G. Eldering, \\ L. P. Giering, and A. W. Hornig \\ Baird-Atomic, Inc. \\ Government Systems Division \\ 125 Middlesex Turnpike \\ Bedford, Massachusetts 01730 \\ Prepared for ERDA under Order No. BE-76-P-1221 \\ for \\ Bartlesville Energy Research Center \\ Bartlesville, Oklahoma \\ ERDA-BERC Staff \\ Harold J'. Coleman, Project Leader \\ Charles J. Thompson, Research Supervisor \\ John S. Ball, Director
}

This report was prepared as an account of work

sponsored by the United States Covernment. Neither the United States nor the United States Energy Research and Development Administration, nor any of Uncis employoes, not any of their contracturs,
subcontractors, of llielf employees, makes any warranty, express or implied, or assumes any legal
wates lisbility or responsibility for the accuracy, completeness or usefulness of any information, apparatus, product or process disclosed, or represents that its use would not
infringe privately owned rights.

Date Published-November 1976

\section{ENERGY RESEARCH AND DEVELOPMENT ADMINISTRATION TECHNICAL INFORMATION CENTER}


The objectives for the ERDA research program on oil identification are to determine, measure, and computerize distinctive properties and related data on crude oils and crude oil residues and establish reliable definitive interrelationships of these diverse properties for improved oil spill "fingerprinting" and identification with a high degree of confidence and applicability.

The ERDA oil identification research project, being conducted at the Bartlesville Energy Research Center (BERC), interfaces with and has provided support to the U.S. Customs office, Coast Guard, and the Environmental Protection Agency. Although much research in this area has been done in both industrial and government laboratories, the development and evaluation of improved analytical techniques and/or diagnostic parameters for oil identification are being continued and with notable successes. The ERDA-sponsored research described in this report represents one facet of cooperative research between government (ERDA-BERC) and industry (Baird-Atomic, Inc.) that is providing improved oil identification technology. The development of new and improved luminescence analysis techniques, including the presentation of total luminescence data in a contour graphic display, provides a viable contribution to the art of oil identification as illustrated by data comparisons on six topped crude oils, selected largely on the basis of widely differing geographical locations in the world.

Although the methodology in this report is currently still in the development stage, the publishing of these initial findings is relevant in providing a basis for continuing research in the scientific community.

Harold J. Coleman Project Leader ERDA-BERC 
TABLE OF CONTENTS

Section

Table of Contents

List of Figures

1. INTRODUCTION

1.1 Background

1.2 Total Luminescence Spectroscopy and Display 1

2. DATA ACQUISITION, REDUCTION AND DISPLAY 3

2.1 Data Acquisition . 3

2.2 Data Reduction 5

2.3 Data Display 7

3. INTERPRETATION OF SPECTRA

3.1 Principal Excitation/Emission Spectra 9

3.2 Identification of Molecular Species of Classes 9

3.3 Establishing Identity of Oil Samples 11

3.4 Conclusions 13

4. RECOMMENDATIONS

4.1 Further Work Using Existing Data Bank 15

4.1.1 Difference Spectra . 15

4.1.2 Logarithmic Display 15

4.1.3 Derivative Spectra 15

4.2 Work Involving Additional Measurements $\quad 16$

4.2.1 Contour Spectra Library of Important Molecular Species

4.2.2 Low Temperature Studies 16

4.2.3 Contour spectra of Chromatographed Fraction

4.2.4 Digital Filter for Second order 17

$\begin{array}{lll}4.2 .5 & \text { Spiked Oils } & 17\end{array}$

$\begin{array}{ll}\text { FIGURES } & 18\end{array}$ 


\begin{tabular}{|c|c|c|}
\hline umber & & Page \\
\hline $1-$ & $\begin{array}{l}\text { UNCORRECTED PRINCIPAL EXCITATION/EMISSION SPECTRA } \\
\text { OF BACHAQUERO, VENZUELA }\end{array}$ & 18 \\
\hline 2- & $\begin{array}{l}\text { UNCORRECTED PRINCIPAL/EXCITATION/EMISSION SPECTRA } \\
\text { OF DURI, INDONESIA }\end{array}$ & 19 \\
\hline $3-$ & $\begin{array}{l}\text { UNCORRECTED PRINCIPAL EXCITATION/EMISSION SPECTRA OF } \\
\text { PRUDHOE BAY, ALASKA }\end{array}$ & 20 \\
\hline $4-$ & $\begin{array}{l}\text { UNCORRECTED PRINCIPAL EXCITATION/EMISSION SPECTRA OF } \\
\text { GACH SARAN, IRAN }\end{array}$ & 21 \\
\hline 5- & $\begin{array}{l}\text { UNCORRECTED PRINCIPAL EXCITATION/EMISSION SPECTRA OF } \\
\text { EL MORGAN, EGYPT }\end{array}$ & 22 \\
\hline $6-$ & $\begin{array}{l}\text { UNCORRECTED PRINCIPAL EXCITATION/EMISSION SPECTRA OF } \\
\text { MINAGISH, KUWAIT }\end{array}$ & 23 \\
\hline 7- & $\begin{array}{l}\text { CORRECTED PRINCIPAL EXCITATION/EMISSION SPECTRA OF } \\
\text { BACHAQUERO, VENZUELA }\end{array}$ & 24 \\
\hline 8-- & $\begin{array}{l}\text { CORRECTED PRINCIPAL EXCITATION/EMISSION SPECTRA OF } \\
\text { DURI, INDONESIA }\end{array}$ & 25 \\
\hline 9- & $\begin{array}{l}\text { CORRECTED PRINCIPAL EXCITATION/EMISSION SPECTRA OF } \\
\text { PRUDHOE BAY, ALASKA }\end{array}$ & 26 \\
\hline $10-$ & $\begin{array}{l}\text { CORRECTED PRINCIPAL EXCITATION/EMISSION SPECTRA OF } \\
\text { GACH, SARAN, IRAN }\end{array}$ & 27 \\
\hline & $\begin{array}{l}\text { CORRECTED PRINCIPAL EXCITATION/EMISSION SPECTRA OF } \\
\text { EL MORGAN, EGYPT }\end{array}$ & 28 \\
\hline $12-$ & $\begin{array}{l}\text { CORRECTED PRINCIPAL EXCITATION/EMISSION SPECTRA OF } \\
\text { MINAGISH, KUWAIT }\end{array}$ & 29 \\
\hline $13-$ & CONTOUR SPECTRUM OF BACHAQUERO, VENEZUELA & 30 \\
\hline $14-$ & CONTOUR SPECTRUM OF DURI, INDONESIA & 31 \\
\hline $15-$ & CONTOUR SPECTRUM OF PRUDHOE BAY, ALASKA & 32 \\
\hline $16-$ & CONTOUR SPECTRUM OF GACH SARAN, IRAN & 33 \\
\hline 17- & CONTOUR SPECTRUM OF EL MORGAN, EGYPT & 34 \\
\hline $18-$ & CONTOUR SPECTRUM OF MINAGISH KUWAIT & 35 \\
\hline 19- & CONTOUR SPECTRUM OF METHYLCYCLOHEXANE & 36 \\
\hline 20- & $\begin{array}{l}\text { UNCO RRECTED PRINCIPAL EXCITATION/EMISSION MAXIMA OF } \\
\text { MODEL COMPOUNDS }\end{array}$ & 37 \\
\hline & OVERLAY OF PRUDHOE BAY, ALASKA AND DURI, INDONESIA & 40 \\
\hline & DIFFERENCE OF DURI, INDONESIA AND PRUDHOE BAY, ALASKA & 41 \\
\hline
\end{tabular}




\subsection{INTRODUCTION}

In this report, prepared for the Bartlesville Energy Research Center under Order No. BE-76-P1221, Baird-Atomic presents the results of a preliminary study of six topped crude oils by total Iuminescence. Included are six contour spectra, six principal excitation/emission spectra, an interpretation of the contours by comparison with other data, a discussion of the method and recommendations for further related studies.

During the course of the work a paper was presented at the Pittsburgh Conference held in Cleveland in March 1976. The title of the paper was THE USE OF TOTAL LUMINESCENCE CONTOUR SPECTRA FOR OIL IDENTIFICATION: authors were $A . W$. Hornig, and $\mathrm{H} . \mathrm{G}$. Eldering of Baird-Atomic, and H. J. Coleman of the Bartlesville Energy Research Center.

\subsection{Background}

The Bureau of Mines has been involved in a continuing program to investigate and evaluate analytical techniques which may provide methods for crude oil spill identification 2,3,4. Techniques previously studied include gas-liquid chromatography, atomic absorption spectrophotometry, infrared spectroscopy, sulfur and nitrogen determinations, mass spectrometry, nuclear magnetic resonance spectroscopy, and ultraviolet spectrophotometry. A recent paper by Wilson et $a l^{5}$ summarizes results and provides an extensive bibliography of related work. Where possible, all methods were applied to the crude oils, topped crudes and residua. Measurements on topped crudes were found to be most useful in identifying weathered samplos.

\subsection{Total Luminescence Spectroscopy (TLS)}

Luminescence analysis is accepted as a sensitive and specific technique for the identification and characterization of petroleum products. Baird-Atomic has been involved in basic and applied studies in this area for more than five years, supported in part by. EPA, Coast Guard, Navy and ERDA. 
Luminescence analysis focusses on the aromatic components of mixtures. Typical methodology involves repetitive scanning of emission spectra for many excitation wavelengths (or the converse) to develop intensity data as a function of excitation and emission wavelengths. This is time-consuming and results in an overwhelming volume of data which must be interpreted by a specialist. The total luminescence information may be displayed in a single graph, for example by contours. Basic luminescence data are taken directIy from a repetitively scanned spectrofluorometer. Use of a computer makes it possible to explore alternative displays and obtain differences, ratios, and correlations involving related spectra. Total luminescence contour graphs of mixtures often resemble human fingerprints, and standard fingerprint matching techniques may be useful. In many cases visual comparison by overlaying spectra is sufficient. Total luminescence data may also be interpreted in terms of the classes of luminescent materials present. In not too complex mixtures, available computer algorithms may be employed to produce single component contours for identification and quantitation.

In the experimental effort described in this report, total luminescence spectra of six topped crudes are presented in contour form.. These particular crudes (Bachaquero, Venezuela; Duri, Indonesia; El Morgan, Egypt, Gach Saran, Iran; Minagish, Kuwait; and Prudhoe Bay, Alaska) have been studied extensively by the ERDA Energy Research Center in Bartlesville Oklahoma, utilizing the techniques listed previously. This program is a first assessment of the potential of total luminescence spectroscopy for oil characterization and identification. 
2.0. DATA ACQUISITION, REDUCTION AND DISPLAY

2.1 Data Acquisition

The basic data on the six oils (Bachaquero, Venezuela; Duri, Indonesia, Prudhoe Bay, Alaska; Gach Saran, Iran; El Morgan, Egypt; Minagish, Kuwait) at a concentration of $10 \mathrm{ppm}$ in methylcyclohexane (Matheson, Coleman and Bell spectroquality) were taken on a BairdAtomic Fluoricord Model FC-100. A $1 \mathrm{~cm}$ square Suprasil fluorescence cell equipped with a Teflon stopper was used. The entrance and exit slits in both excitation and emission were $10 \mathrm{~nm}$ and the data were taken at a scan rate of $2 \mathrm{~nm} / \mathrm{sec}$. The fluorescence channel was equipped with a Hamamatsu R 446 photomultiplier tube to increase red response. The monitor channel was equipped with an RCA 1 P28 photomultiplier tube. Emission spectra on the six oils were taken at $5 \mathrm{~nm}$ intervals in excitation starting at $550 \mathrm{~nm}$ and decreasing by $5 \mathrm{~nm}$ decrements to $250 \mathrm{~nm}$. The emission scan covered the range. 250-750 nm. The fine gain on the fluorescence channel was maintained at 10 and the coarse gain was changed to give maximum emission intensity on the graph paper. The gain of the monitor channel was adjusted at various regions of the spectrum so that the intensity did.not fall to less than $30 \%$ of full scale. This decreased the error in the monitor channel correction. A plastic fluorescence standard of tetraphenylbutadiene (peak at excitation $360 \mathrm{~nm}$, emission $426 \mathrm{~nm}$ ) was used to optimize the operating conditions of the Fluoricord at the beginning of each run and was also used periodically during the data collection to make sure there were no arc shifts.

A PDP interface module provided a means of digitizing the analog information from the Fluoricord and loading the digitized information into a PDP 8 minicomputer. Digitization occurred 60 times a second with readout intervals of every two seconds so that spectral data from the Fluoricord were displayed on and punched on paper tape in octal format every $4 \mathrm{~nm}$. With a resolution of $10 \mathrm{~nm}$, and the absence of sharp peaks in the oil emission, an adequate description of the oil emission could be made from this data density. The digitized data were taken to the IBM $1130 \mathrm{com}-$ 
puter for correction and contouring. Correction removed the wavelength dependence of the spectrofluorimeter.

The calibration and spectral response of the Baird-Atomic Fluoricord was determined from the following set of measurements. A low pressure mercury arc was used to calibrate the wavelength of both the excitation and emission monochromators. The intensity of excitation radiation was measured with a triangular cuvette containing a solution of 10 grams/liter Rhodamine $B$ in ethylene glycol. This cuvette was placed in the right angle sample position and the emission monochromator set at the peak emission for Rhodamine $B$. The excitation spectrum was then measured and recorded on paper tape for later use in generating the calibration curves. Rhodamine $B$ in concentrated solution acts as a quantum counter, and its excitation spectrum is proportional to the quanta of excitation radiation per unit bandwidth.

The emission spectral response of the Fluoricord was obtained in the following manner. Emission and excitation monochromator were synchronously scanned from 250 to $580 \mathrm{~nm}$ with excitation wavelength set equal to the emission wavelength. A barium sulfate scatterer was placed in the sample position. For this calibration $10 \mathrm{~nm}$ slits in both excitation and emission were used. (The use of a wider exit slit in emission resulted in no difference in the spectral output.) The normalized scattering spectrum is proportional to the spectral response of the emission monochromator photomultiplier unit after corrections for variations in light intensity (monitor channel), and the spectral distribution of the excitation radiation. In order to obtain the spectral response of the Fluoricord beyond $580 \mathrm{~nm}$, the output of a 200-W quartz-iodine lamp with a coiled tungsten filament operating 6.5 amps (about $3000^{\circ} \mathrm{K}$ ) was used. Based on the standard spectral irradiance established by the National Bureau of Standards a spectral response curve for the Fluoricord out to $750 \mathrm{~nm}$ was determined. The quartz-iodine output was corrected to quanta versus wavelength. From the two curves an intersection point at $442.3 \mathrm{~nm}$ was determined and a spectral response curve over the entire region 250-750 nm was gen- 
erated.

The primary fluorescence data on six oils, punched on paper tape, were taken to the IBM 1130 computer where they were corrected for variations in lamp intensity, intensity distribution of exciting light and the emission response of the Fluoricord, using a Baird-Atomic propriety computer program. The corrected spectra were then put into an IBM Contour Map Plotting (1130-CX-11X) Program to obtain corrected contours.

\subsection{Data Reduction}

As stated above, data acquisition for each sample involved an output of sixty-one uncorrected emission scans and a paper tape containing the digitized data. Throughout the runs, comments were entered on the tape via the teletype keyboard. These included sample name, exciting wavelength, gain parameters and other experimental notes. To facilitate the editing of comments and other superfluous entries from the digitized data and the insertion of parameter information, the paper tape was converted to a deck 2000 computer cards. The fluorescence correction program (FLCMP) accepted the edited cards and generated emission scans corrected for the intensity distribution of exciting light, temporal variations in lamp intensity, and the emission response of the Fluoricord.' Simultaneously, a card deck containing 8,000 emission point intensities in a format compatible with the contour map plotting program was punched.

Because the Numerical Surface Techniques and Contour Map Plotting Package (NST/CMP) had an internal input restriction of 1000 data points, the available data had to be reduced by hand to a fraction of its original size and mathematically smoothed before contour plotting. Contours obtained in this manner were presented at the Pittsburgh Conference.

Use of but a small fraction of input data and inaccessibility of information except by card input were felt to be unacceptable limitations. Therefore, Baird-Atomic elected to revise the above- 
outlined procedure with a development of more sophisticated data handling programs, using our own Research and Development funds. This extra effort delayed the final report, but resulted in in-. creased efficiency and accuracy of the procedure for this and future efforts in oil identification.

Overcoming the input restriction of 1000 data points proved to be a complex problem in that 1008 of the normal input programs of the Numerical surface Techniques and Contour Map Plotting Package had to be by-passed to make the contouring of large data sets possible. The normal input stream to the contour phase of NST/CMP consisted of LODAR, a random data set card loading routine with a 1599 data point capability and then NUPRX, a program which calculated a well defined grid from the random data. The latter program was the limiting portion of the input stream with a maximum of 1000 data points allowable on input. The resultant grid size from NUPRX was $100 \times 100$, but through the use of another portion of NST/CMP called FINGR, a $199 \times 199$ dimension was possible, meaning that the ultimate grid size limit of the contouring phase was $199 \times 199$ or approximately 40,000 data points per contour.

At the completion of the revision effort, the storage and contouring of the maximum size grids was achieved. A disk storage subroutine was added to the FLCMP program which packed the data into disk files with an address system allowing direct access to all of the fluorescence information for any chosen oil within seconds. This subroutine also avoided the massive card outputs of earlier work and facilitated efficient data editing. The program which completed the revised procedure was ERDOP. This package provided access to the disk data files, and by-passed the normal input stream of NST/CMP by depositing the desired data in the fixed storage area of the NST/CMP program where it expected to find the contour data. 


\subsection{Data Display}

While the chief output of this program is a collection of. corrected contour spectra of the six topped crudes under study, we also present a more traditional display of individual excitation and emission traces: Using an uncorrected single monochromator spectrofluorometer on a mixture, the most common display would be an emission trace excited at the wavelength producing the most intense emission, and a corresponding excitation trace when monitored at the peak emission. This combination we call "principle excitation/emission spectra". While such a pair does not document the full luminescence of the mixture, it is a convenient simple presentation. "The uncorrected principle excitation/emission traces for the six topped crude oils studied in this program are given in Figures 1-6. Corrected versions of these traces are presented in Figures 7-12: The interpretation of these spectra will be discussed in section 3.1 .

Total luminescence data may be displayed in several ways. Isometric projections are most useful for structural detail; however, several such plots may be necessary to see the three dimensional plot from all directions. A second useful display utilizes contours, much as in a geological survey map. A single contour map contains all views of the three-dimensional figure. While the contour plot is in some ways more general, it suffers from difficulty in interpretation of structural detail (which becomes contour density). Contour display was chosen of necessity, since our software library does not contain an isometric projecLiun program.

Several variants of contour display may be selected. Besides plotting the intensity, one may select the logarithm of the intensity; or the difference in intensity for two samples, or a ratio. For this first study, the simple intensity was used.

For the contour graphs of Figures 13-18 a contour interval of 0.025 was selected, representing $21 / 28$ of the normalized 
peak intensity between neighboring contours. This results in forty contours per graph--a reasonable compromise between visual clarity and detail.

Another question arose concerning the Rayleigh and Raman scattering of the methylcyclohexane solvent, clearly evident at the gains employed. In order to subtract off this background a contour plot of the scattering of methylcyclohexane was obtained (Figure 19) and employed for background subtract in the contours of Figures 13-18.

Since the more sophisticated program allowed use of the full data, it was not necessary to apply a smoothing routine (as for the Pittsburgh traces).

A remaining defect in the final contours lies in the second order spectra which occur in a triangle at the lower right-hand portion of each graph. The second-order spectra serve to mask any low-intensity first-order data on large molecules which may be there. While filters could have been used, in principle, to eliminate the second order data, the complexity of using and compensating for many filters precluded their use. One of the recommendations of section 4 deals with this problem.

Interpretation of contour spectra is discussed in sections 3.2 and 3.3 . 
3.0 INTERPRETATION OF SPECTRA

3.1 Principal Excitation/Emission Spectra

Uncorrected principal excitation/emission spectra for the six topped crudes are given in Figures 1-6. In each trace, the left-hand trace is the principle excitation spectrum; the righthand trace is principle emission. It will be observed that the traces are quite similar. The largest differenre is in intensity, which causes the sharp Raman peaks to vary in apparent resolution. The excitation/emission maxima occur at approximately $335 \mathrm{~nm}$ and $390 \mathrm{~nm}$ for all but Prudhoe Bay (Figure 3) where excitation and emission have shifted to slightly shorter wavelengths, and Minagish, where the shift is to longer wavelengths. The intensity difference cannot be used as primary identification, since it depends too much on the details of topping. The variation in apparent peak position may be useful, but is not sufficient in most cases.

In Figures 7-12 we give corrected versions of the previous six figures. There is, in fact, no new information here, although some hint of structure is brought out in the excitation traces. These traces are presented as typical inputs for the contour spectra to be discussed in the next section. Note the large effect on amplitude and position of the short wavelength excitation spectrum, due to the large correction necessary in this region. Note also that on a corrected basis these spectra are no longer "principle" in the sense they do not represent spectra through the corrected maxima.

\subsection{Identification of Molecular Species or Classes}

For single materials, or simple mixtures (sufficiently dilute to minimize energy transfer) the total luminescence spectra are expected to be the sums of those of the individual molecular species. Very complex mixtures are expected to result in broad structureless spectra because of contributions from components with slightly displaced spectra. It was hoped that at a concentration of ten parts per million, decoupling of species would be 
complete and.some identification would be possible in the topped oils without further separation.

Intercomparison of the spectra of Figures 13-18 reveals great similarities. All are characterized by a peak emission at approximately $360 \mathrm{~nm}$ with an excitation (off the graph) of less than $245 \mathrm{~nm}$. There is also a related but lesser peak with emission at approximately $370 \mathrm{~nm}$ and excitation of approximately $260 \mathrm{~nm}$. There is also a characteristic peak at an emission of about $320 \mathrm{~nm}$ and a corresponding excitation of about $275 \mathrm{~nm}$. Finally, their are characteristic ridges present in all traces to varying degrees. One ridge is roughly parallel to the emission axis at an excitation just over $260 \mathrm{~nm}$. Another is roughly at $45^{\circ}$ with emission at approximately $50 \mathrm{~nm}$ greater than the corresponding excitation. A first general conclusion would be that the multiplicity of components has erased highly specific structural details related to individual molecules.

As an example of how classes of compounds may be identified, we have plotted in Figure 20 the approximate location of luminescencepeaks of a number of materials previously associated with high boiling fractions. These data, (Table 1), from McKay \& Latham 3,4, were taken on an uncorrected single monochromator spectrofluorometer. in cyclohexane at room temperature. While some displacement of peaks at short wavelengths is expected between corrected and uncorrected spectra, these data serve to suggest what materials may be associated with structure in contours. No significant differences are expected between spectra taken in methylcyclohexane and cyclohexane. When any contour spectra is overlaid on Figure 20 it is apparent that most of the materials fall in regions where contours are relatively uniform. Thus there is little indication about the presence of these materials. However, several possible identifications can be made.

Naphthalene (b) lies in the middle of the left-most feature of the oil contours, suggesting that naphthalenic compounds are common to all the oils and contribute strongly to this observed 
feature. Pyrene (p) appears on the prominent $45^{\circ}$ ridge, suggesting that it is present and measured in all samples. A benzofluorene ( $f$ ), several benzo-carbazoles $(h, i)$, triphenylene (g) and chrysene ( $j$ ) all have emission in the region which could contribute to the large maximum with its excitation peak off the scale. In this case the uncorrected nature of the latter data could lead to an erroneous assignement of peak excitation, and compounds in this group are possible contributors to the large peak. As expected, volatile small molecules like benzene (d'), toluene $\left(e^{\prime}\right)$ and xylenes ( $f^{\prime}$ ) are not detected in the topped oils. The above suggestive identifications are not at all quantitative. What would be of great value is a set of contours of model compounds in an oil-like aliphatic matrix. These could. be compared visually or by computer with features in an oil contour. Or oils could be spiked with model compounds (at known concentrations). The original and spiked oils could then be compared, in order to establish the effect of a known concentration of model compound in a given oil. This would reveal whether quenching or energy transfer phenomena were still effective. These approaches are listed as recommendations in section 4 .

\subsection{Establishing Identity of Oil Samples}

The most common practical problem encountered is that of establishing probable identity between an unknown oil sample and one of several known oils. Such identification may be entirely phenomenological, without real knowledge of the molecular species responsible for spectral features.

Comparing any two sets of contours of the six oils studied, it appears at first that they are quite similar. Certainly there are intense common features, against which small differences must be evaluated. Close comparison of spectra shows numerous differences. As an example, in Figure 21 we have superposed the spectra of Duri, Indonesia (Figure 14) and Prudhoe Bay, Alaska (Figure 15). While the precision of our contouring has not been established, it is clear that many features of the contours are radically different. We call attention to spectral regions, de- 
lineated by a triangle and rectangle. In the rectangle we see that the ridge in one of the oils (Duri) is much more pronounced than in the other. In the triangular region the contour lines cross at angles approaching $90^{\circ}$, indicating decided differences, although the exact meaning is difficult to define without further study. Closer examination reveals other features which clearly differentiate the oils.

While the superposition technique is useful in identifying spectral regions, and it can be accomplished easily with transparencies, an actual difference is much to be preferred. In Figure 22 we produce a difference contour spectrum, generated by the computer. The difference contours are much more suggestive of spectra of a few materials. Thus the emissions at about $430 \mathrm{~nm}$ with excitations at 260,290 , and $360 \mathrm{~nm}$ are suggestive of a compound like benzo(rst)pentaphene, while the emission at $340 \mathrm{~nm}$, with excitations at 250 and $285 \mathrm{~nm}$ may be related to $11-\mathrm{H}$-benzo(b) fluorene for example. In any case, it is clear difference spectra can be very useful in establishing identities of materials present at different concentrations. The results with difference spectra depend strongly on the normalization used. In this case the contours for each individual oil were normalized at their points of maximum emission--and these do not quite coincide.

While difference spectra seem most useful, several other criteria for establishing identity, or classifying samples may be listed. Peak emission intensity varied by almost a factor of two with Prudhoe Bay exhibiting the strongest peak emission and Minagish the lowest. Since emission intensity probably depends strongly on the topping procedure, intensity should only be used as a confirming indicator. The general shape of the luminescence "hill" may be measured in various ways. Thus the position of the 20th contour may be used as an index of half-width. Or the position of the lowest contour in the upper right hand part of the graph may be used to order the traces. With further study numerous "ridges" can be seen. There is structure along a ridge which varies from oil to oil. 


\subsection{Conclusions}

The corrected total luminescence contours for six topped crude oils, presented in this report, represent the first attempt at exploiting this potentially powerful technique for oil classification and identification. Several general conclusions may be drawn about the utility of the graphs presented, and the potential of future work.

It is clear that the great multiplicity of aromatics present in the samples precludes detailed analysis via a simple contour graph. Further, all topped crudes have many similar materials present; therefore, the contour spectra are dominated by common structure: Nevertheless, the contours presented contain a wealth of information. They can certainly be used to establish identity or non-identity by simple overlay. If spectral peaks of model compounds are plotted on the same grid, overlay can establish likely classes of materials. Overlay of contours of differing oils suggests spectral regions of greatest difference, which can again be interpreted in terms of classes of compounds. Difference spectra promise to provide information which may lead to identification of prominent aromatics present in different proportions in oil pairs. To exploit this possibility it will be necessary to develop a library of contour spectra of model compounds which can be compared visually by overlay, or by computer correlation. It may also be necessary to develop a library of a typical oil spiked with known concentrations of model compounds. This will define how an adder sompound appears in an oil matrix.

This preliminary effort has not included other parameters which may produce additional useful results. Thus, a contour plot of the logarithm of intensity would considerably extend the dynamic range to include weakly emitting materials. Detailed "cuts" through the most informative parts of the plane would allow better comparison of structure. Derivative displays would enhance small shoulders on the generally broad curves. Low temperature 
luminescence would not only sharpen and induce structure, but phosphorescence spectra would become available for further identification. Study at a lower concentration would further decouple different materials and would yield more information on the most prominent components. Studies at higher concentrations would give more information on weak emitters and those emitting at longer wavelengths.

It is clear that much remains to be done in exploiting the full possibilities of the total luminescence method. Potential instrumentation can provide contour output in minutes (rather than many hours as at present), allowing useful exploitation of these parameters. Full use of the associated computer can lead to computer correlation (rather than visual estimation) to further broaden the scope of the study.

Several of the above alternatives are discussed briefly in the recommendations of section 4.0 . 


\subsection{RECOMMENDATIONS}

While the contour spectra of the six topped crudes studied in this program seem remarkably similar at first glance, more careful study shows significant differences, all of which are not brought out by the simple contours presented in this report. Simple contours seem most useful in differentiating between grossly different mixtures, and in indicating spectral regions meriting further study.

Recommendations for further work fall into two categories. The first involves exploitation of the data bank already assembled in the computer. The second involves taking new data. Explicit recommendations in each category are given below.

\subsection{Further Work Using Existing Data Bank}

4.1.1 Difference Spectra: The difference spectrum of two identical oils will be featureless. Any small difference in luminescing aromatic content will be evident and it is possible identification of the differing material can be made. An optimum difference spectrum depends on the normalization chosen. It is recommended that the fifteen possible combinations of the original six topped crudes be studied by taking difference spectra. Various normalizations should be attempted to bring out maximum information. This work can be performed without taking of additional data.

4.1.2 Logarithmic Display: In the contour display chosen the interval between contours is $21 / 28$. This was chosen to produce maximum information without too great contour density for visual interpretation. A display which plots contours of the logarithm of intensity would increase the dynamic range. This would allow evaluation of: information below 2 1/2\% of the maximum--infor-: mation which is now disregarded. This work can be performed without taking of additional data.

4.1.3 Derivative Spectra: While contour spectra indicate spectral regions of maximum interest, they are difficult to interpret directly. It is recommended that regions of particular in- 
terest be documented with ordinary amplitude displays through selected cuts. Further, these displays should be presented as derivatives, in order to accentuate shoulders and small variations in the broad oil luminescence. This work can be performed without taking of additional data.

\subsection{Work Involving Additional Measurements}

4.2.1 Contour Spectra Library of Important Molecular Species: The simple plotting of uncorrected peaks of important compounds found in oil, as given in Figure 20 , has been of obvious use. For future use it would be most valuable to assemble a library of corrected contour spectra of important identifying molecular species. These spectra could be used as overlays, or for computer correlation.

4.2.2 Low Temperature Studies: Prior work at Baird-Atomic on oils, pesticides and other mixtures has demonstrated the value of measurements at $77^{\circ} \mathrm{K}$ (Iiquid nitrogen). At this temperature considerable sharpening of some spectral components results, and a new spectrum--phosphorescence--becomes available. In difficult cases, such as the topped crudes, this approach should be valuable. It is recommended that three of the most similar crudes be examined at low temperature to evaluate the additional identifying information produced. Data would be taken as before, except that the sample would be maintained at $77^{\circ} \mathrm{K}$ in a dewar.

4.2.3 Contour Spectra of Chromatographed Fractions: In paper ${ }^{6} \# 406$ at the last Pittsburgh Conference (IDENTIFICATION OF OIL COMPONENTS BY GAS CHROMATOGRAPHY FOLLOWED BY LOW TEMPERATURE LUMINESCENCE ANALYSIS BY J. T. Brownrigg and A. W. Hornig) it was demonstrated that simple chromatographic separation of an oil sample into a small number of fractions resulted in greatly increased luminescence information. It is recommended that this technique be applied to several of. the most similar topped crudes, and room temperature contour spectra be developed for the fractions. It may be desirable to extend measurements to low temperature. 
4.2.4 Digital Filter for Second Order: The contour spectra generated for this report all suffered from second order spectra (lower right-hand section of contour plot) which masked real data possibly present from large molecules. Ordinarily such spectra are removed by inserting filters, matched to the spectral region. This is difficult for contour spectra since a sequence of filters must be used for each sample, and careful intensity matching must be achieved. A more general technique involves determining instrumental response to second order, storing this information in the computer, and performing a computer correction to remove second order. It is recommended that basic data be taken for this correction and a demonstration be performed on a selected oil.

\subsubsection{Spiked Oils: This task is a complement to 4.2.1} where contour spectra of model species are obtained. It is of importance to know whether such model species contribute in a simple additive fashion to the total luminescence. Therefore, it is recommended that several of the model compounds be added to one of the six topped crudes at a reasonable level and the resulting contour spectrum produced. The difference contour spectrum between the spiked and original oil should then be compared to the model oil and interpreted. 


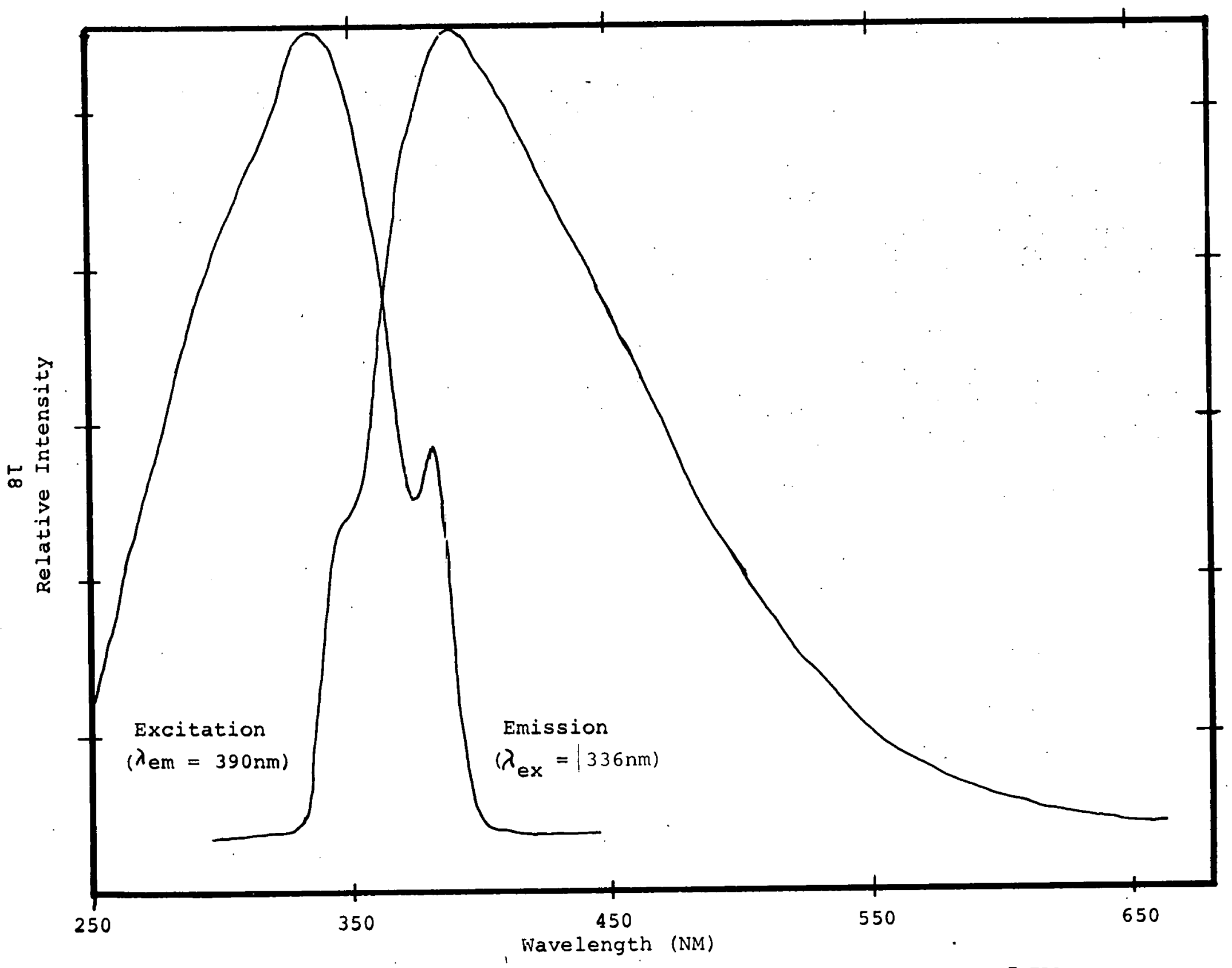

FIGURE 1. UNCORRECTED PRINCIPAL EXCITATION/EMISSION SPECTRA OF BACHAQUERO, VENEZUELA

(10 ppm IN METHYLCYCLOHEXANE) 


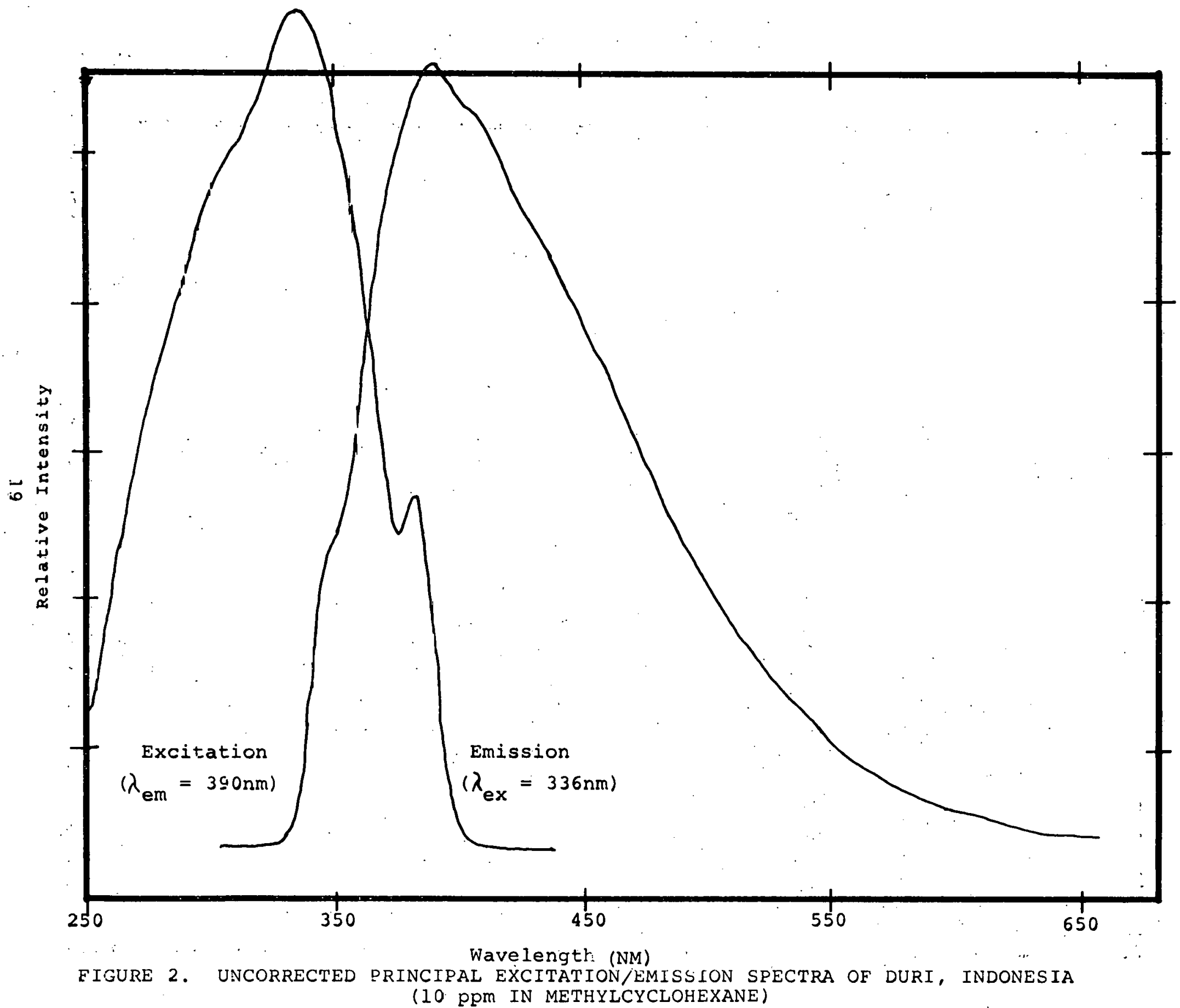




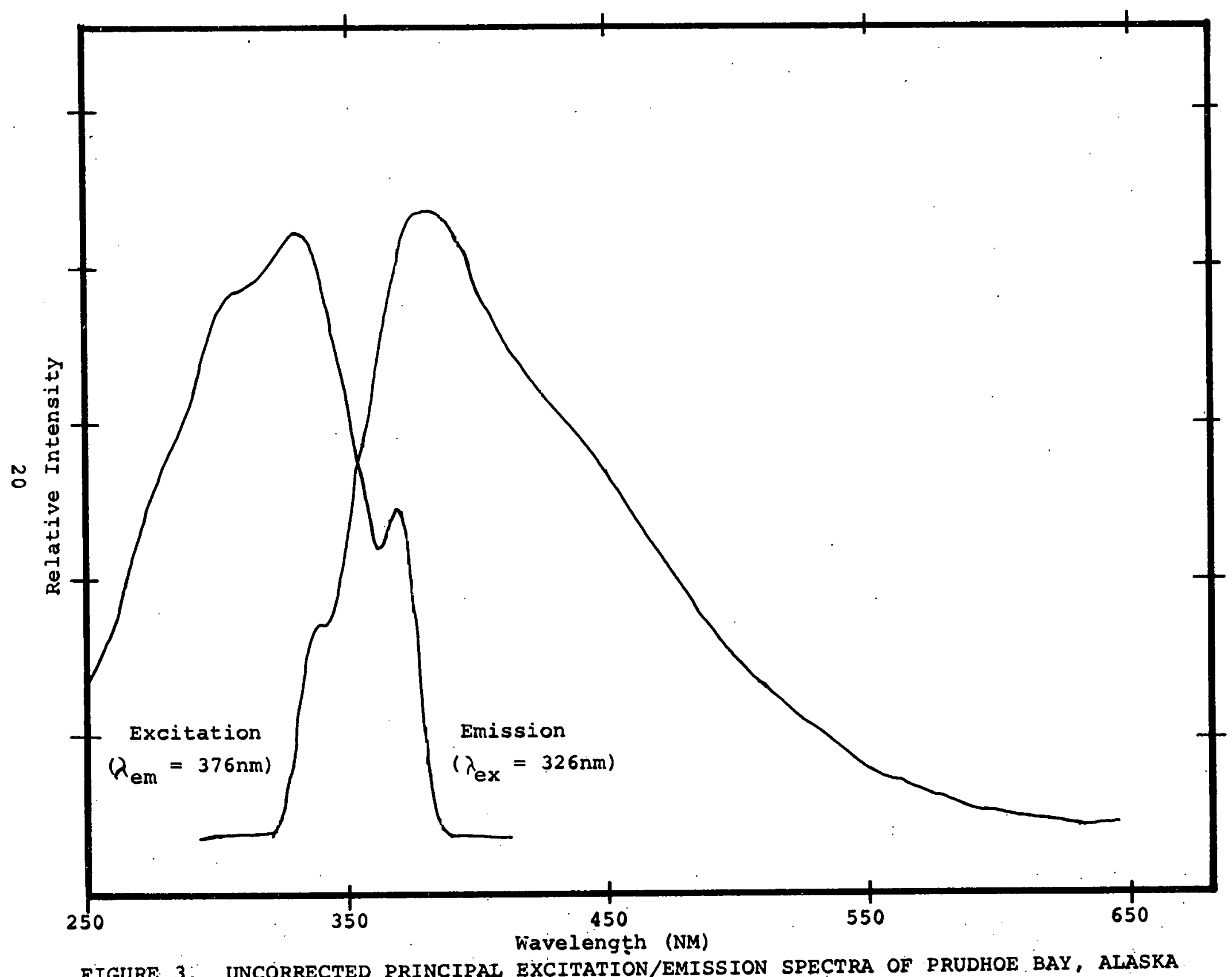

FIGURE 3. UNCORRECTED PRINCIPAL EXCITATION/EMISSION SPECTRA OF PRUDHOE BAY, ALASKA (10 ppm. IN METHYLCYCLOHEXANE) 


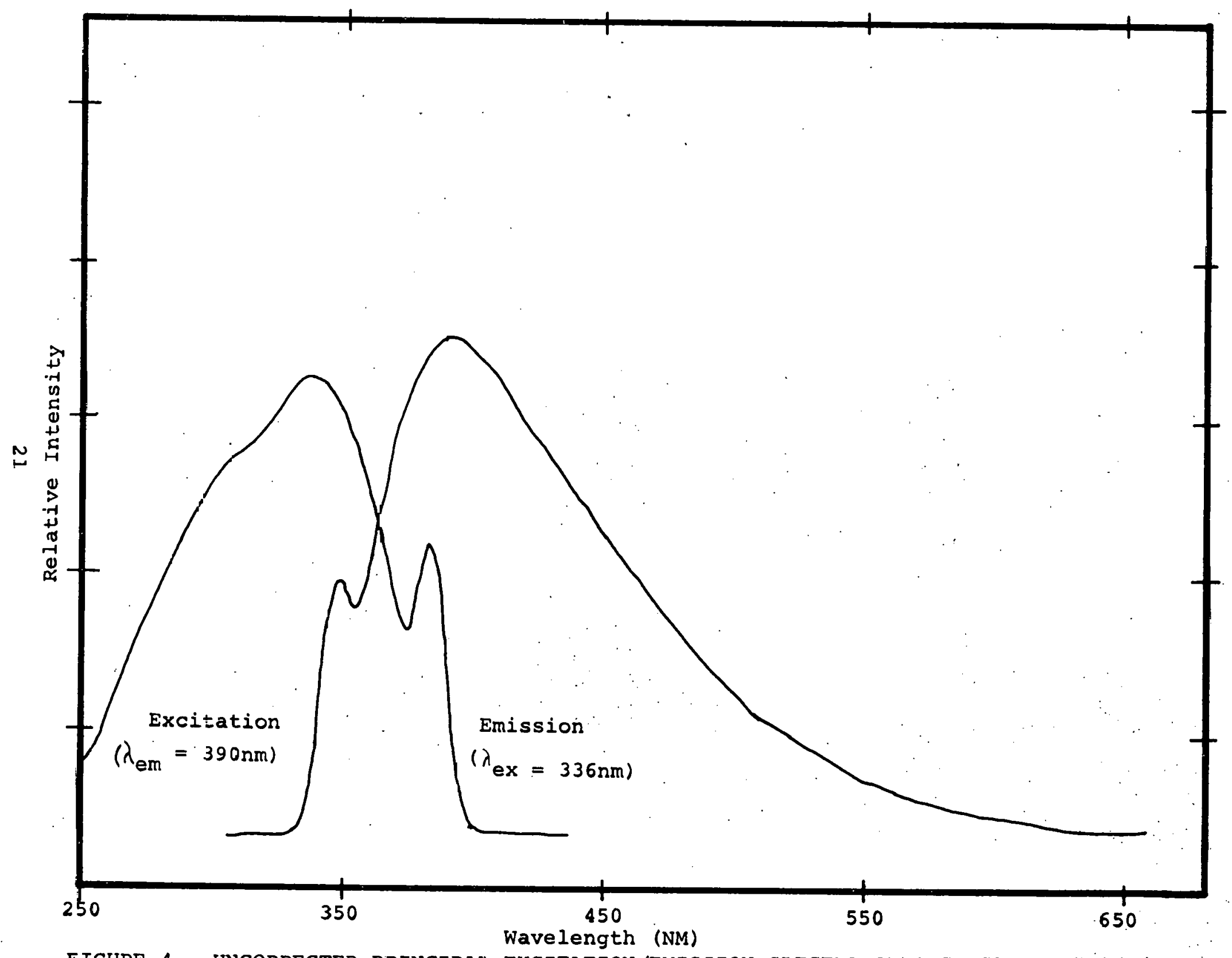

FIGURE 4. UNCORRECTED PRINCIPAL EXCITATION/EMISSION SPECTRA OF GACH SARAN, IRAN (10 ppm IN METHYLCYCLOHEXANE) 


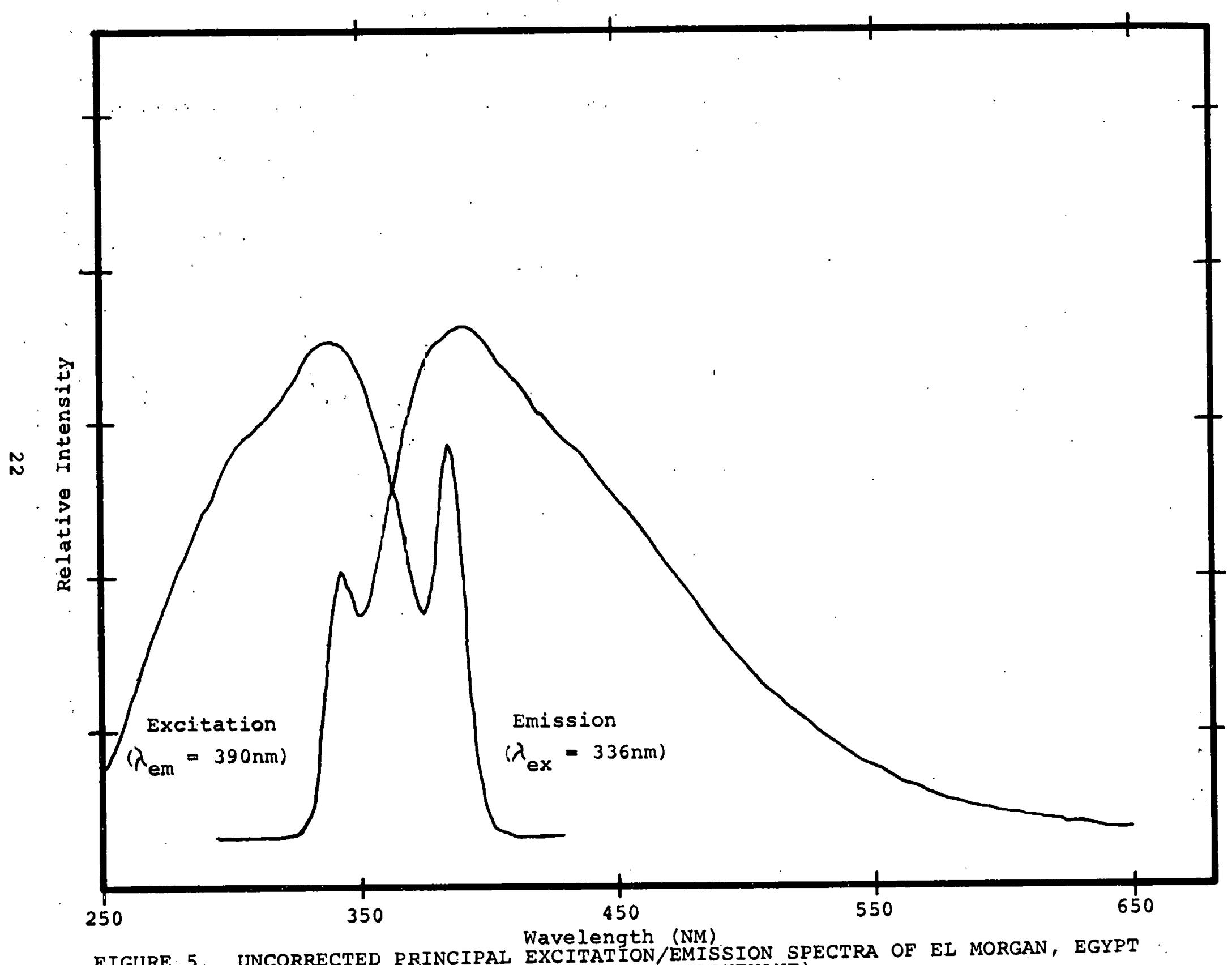

FIGURE 5. UNCORRECTED PRINCIPAI EXCITATION/EMISSION SPECTRA OF EL MORGAN, EGYPT ( 10 ppm IN METHYLCYCLOHEXANE) 


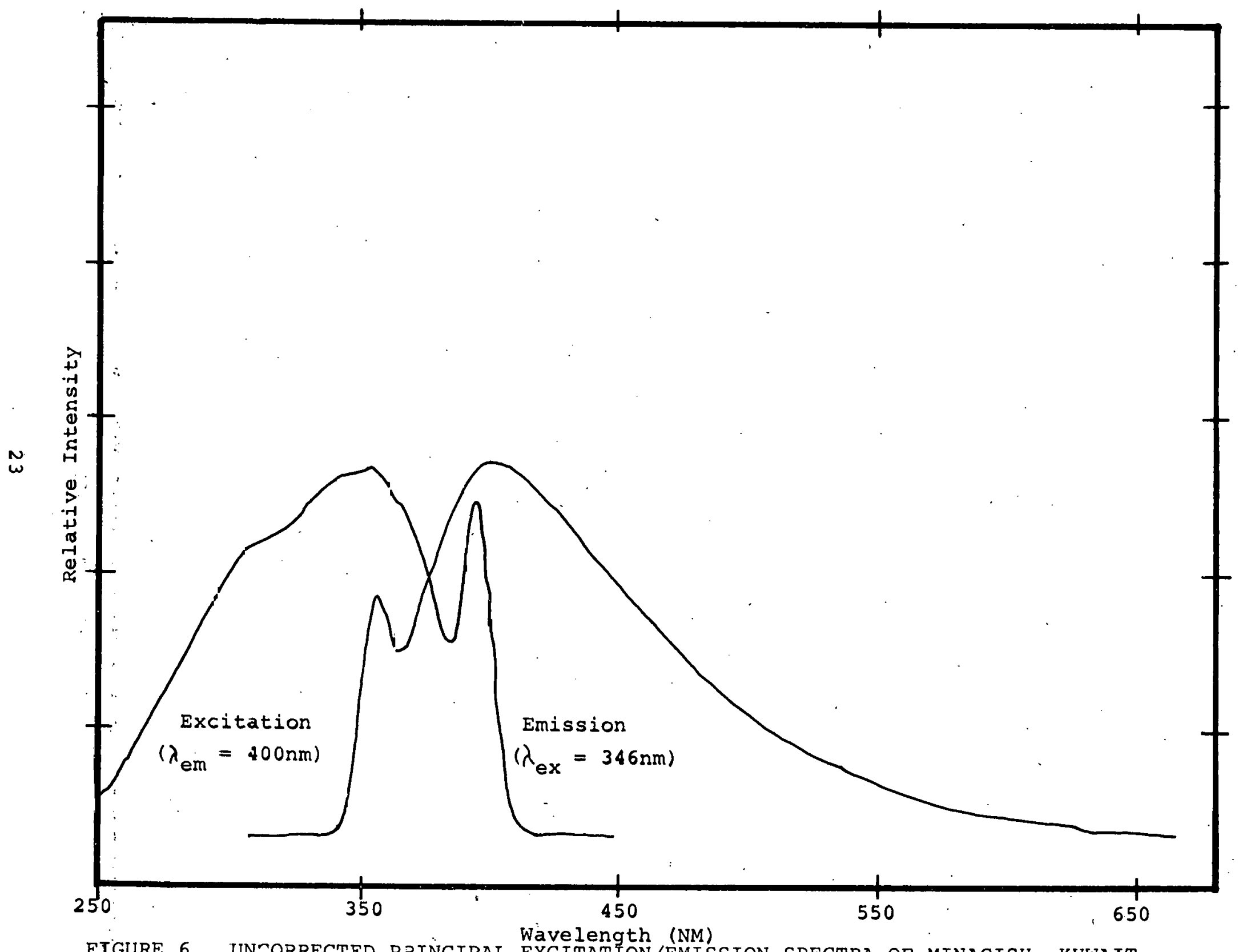

FIGURE 6. UNCORRECTED PRINCIPAL EXCITATION/EMISSION SPECTRA OF MINAGISH, KUWAIT

(10 ppm IN METHYLCYCLOHEXANE) 


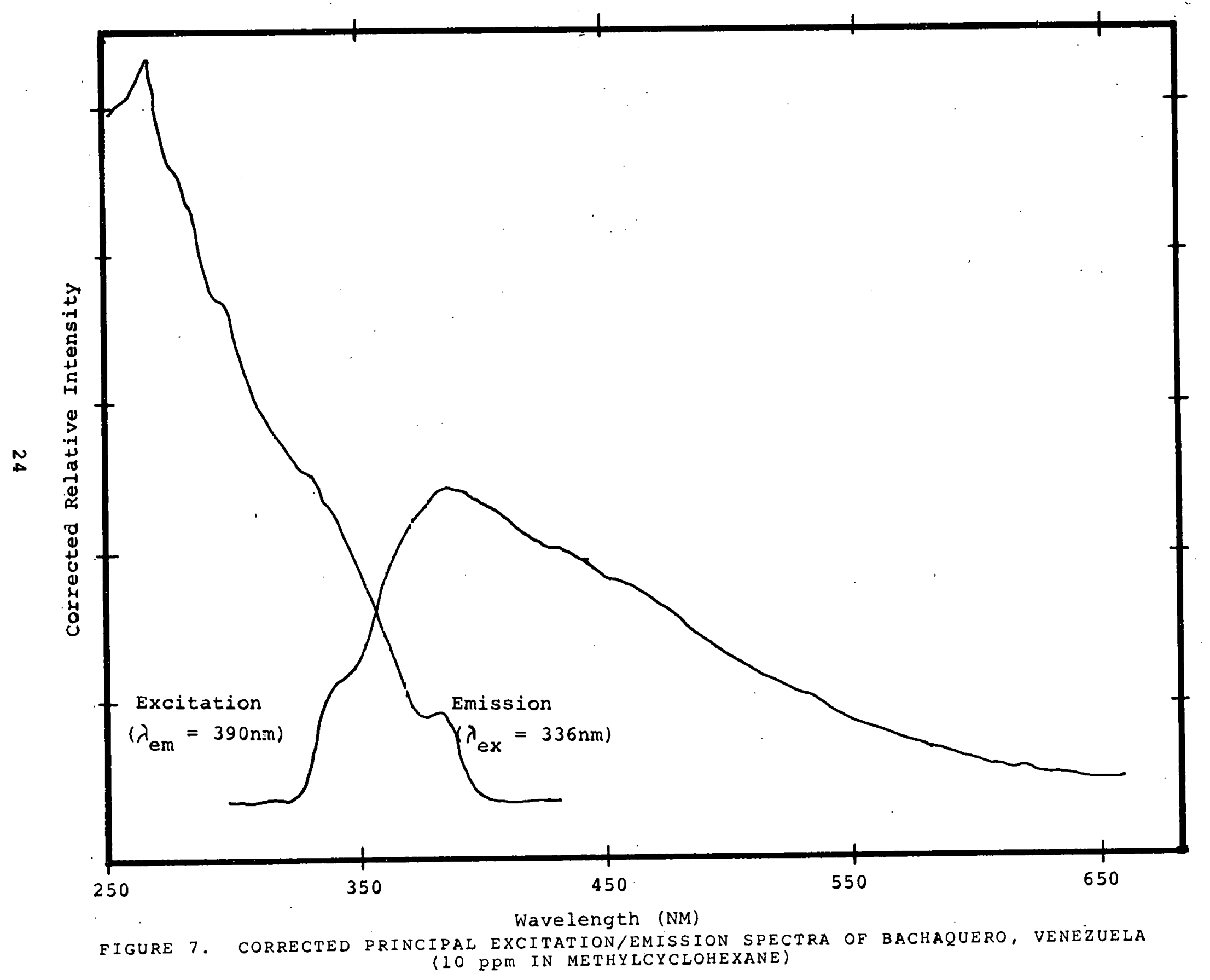




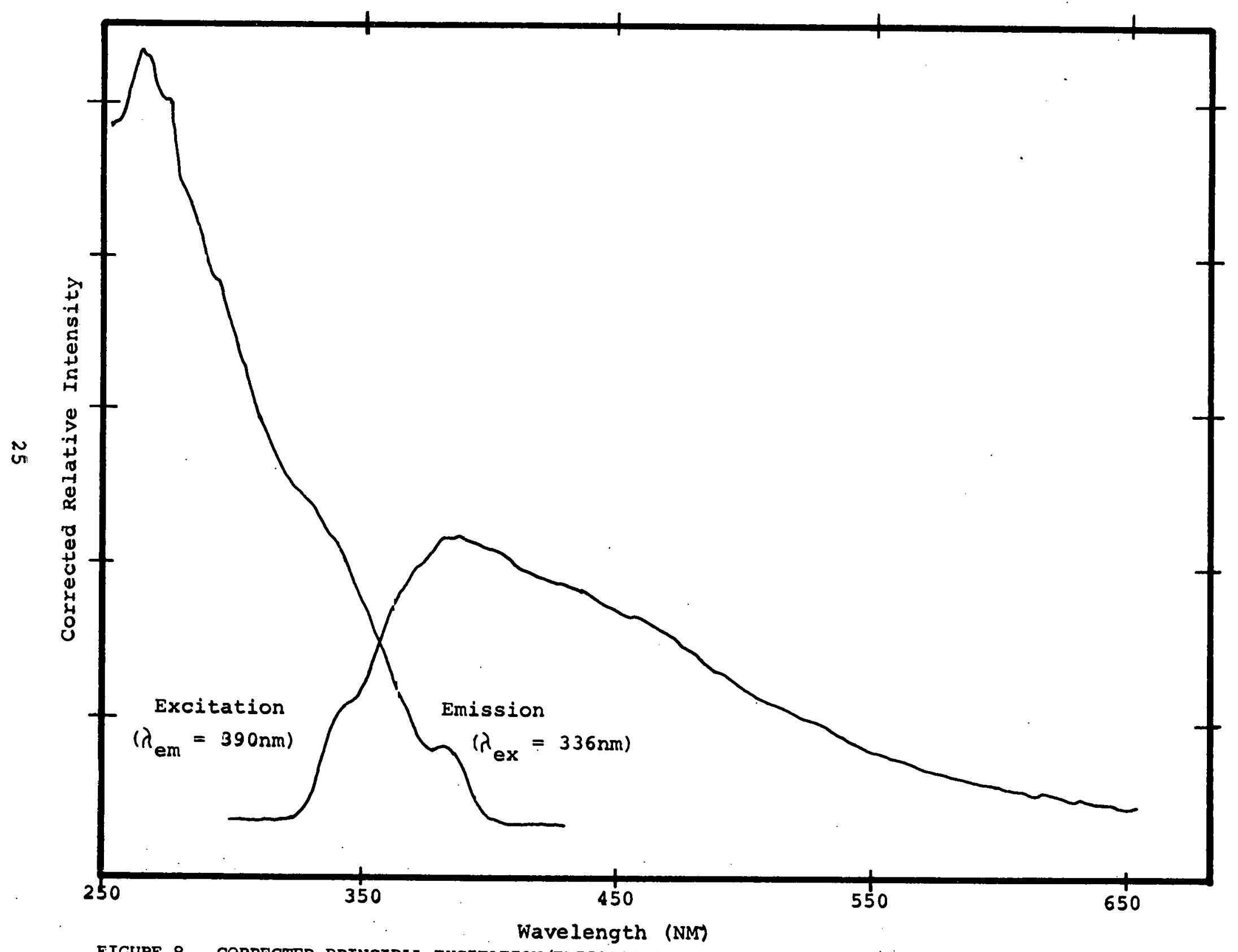

FIGURE 8. CORRECTED PRINCIPRL EXCITATION/EMISSION SPECTRA OF DURI, INDONESIA

(10 ppm IN METHYLCYCLOHEXANE) 


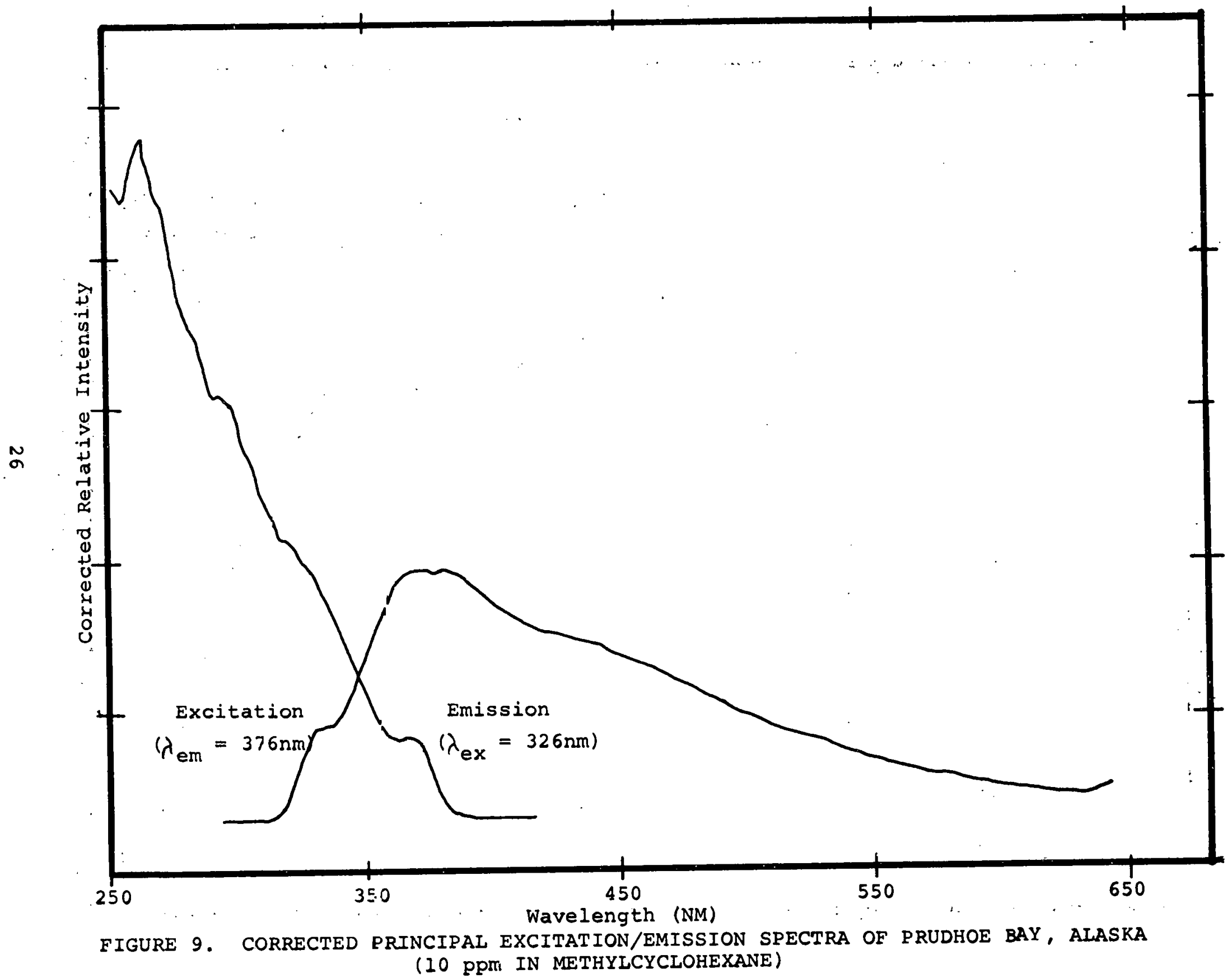




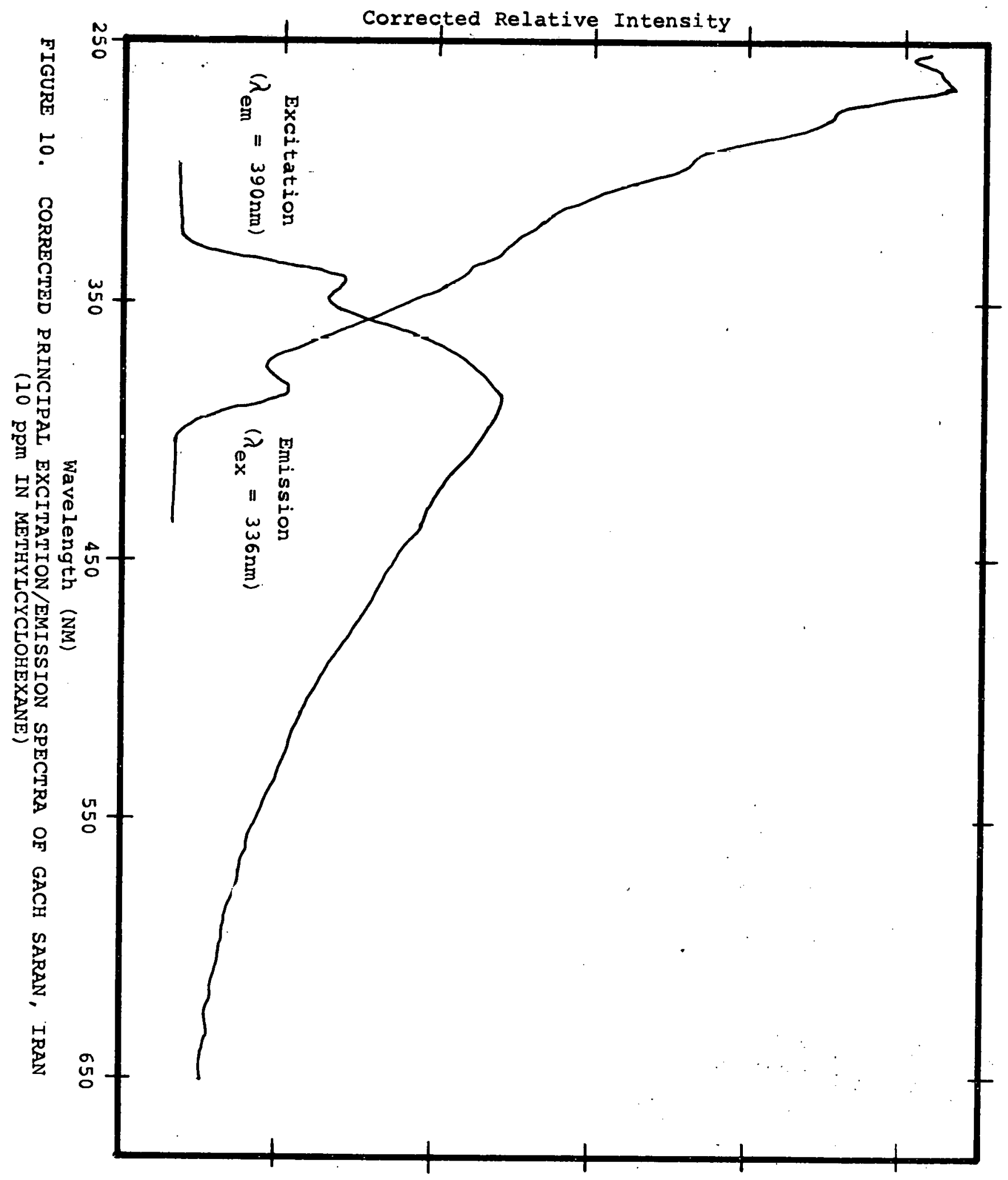




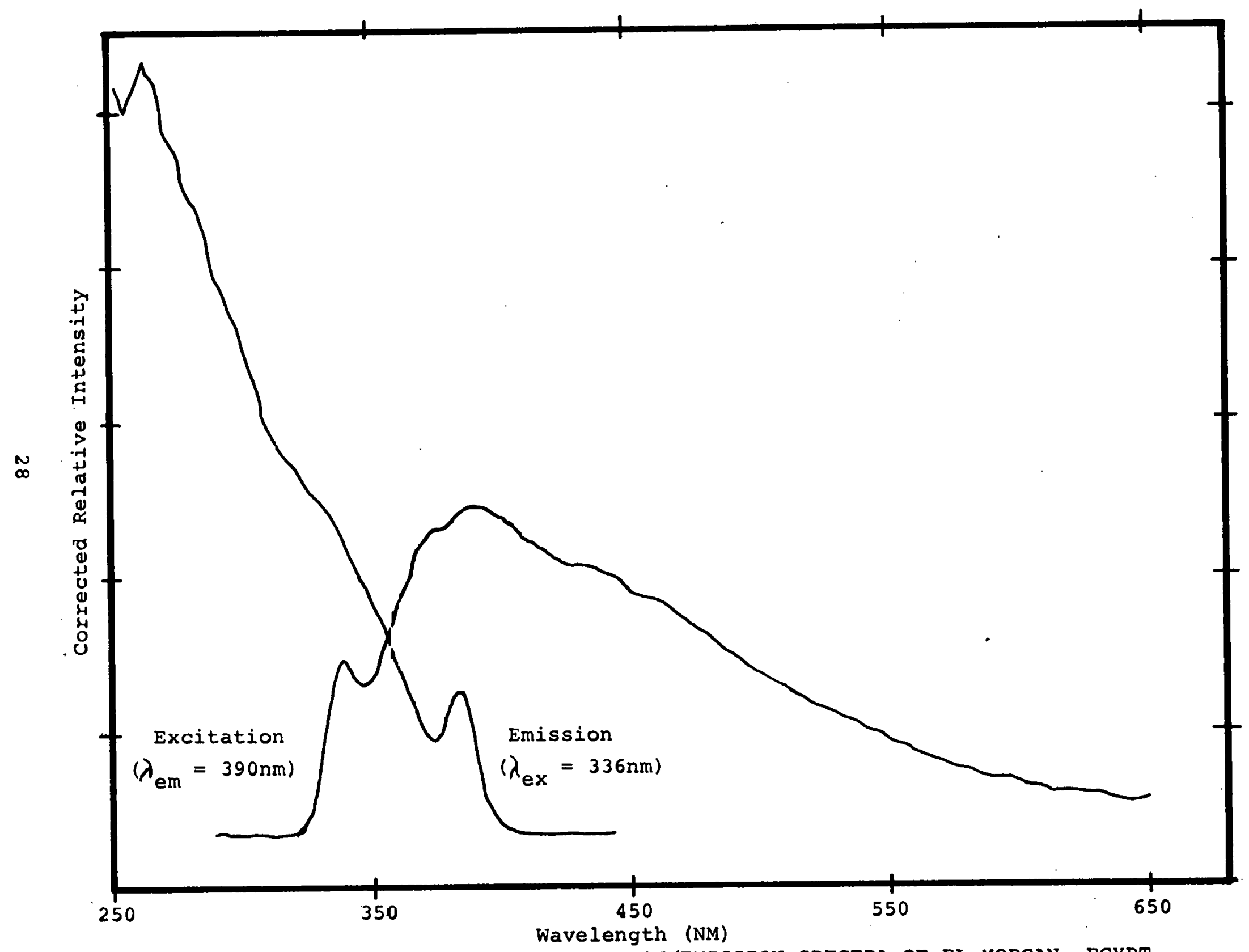

FIGURE 11. CORRECTED PRINCIPAL EXCITATION/EMISSION SPECTRA OF EL MORGAN, EGYPT (10 pPM IN METHYLCYCLOHEXANE) 


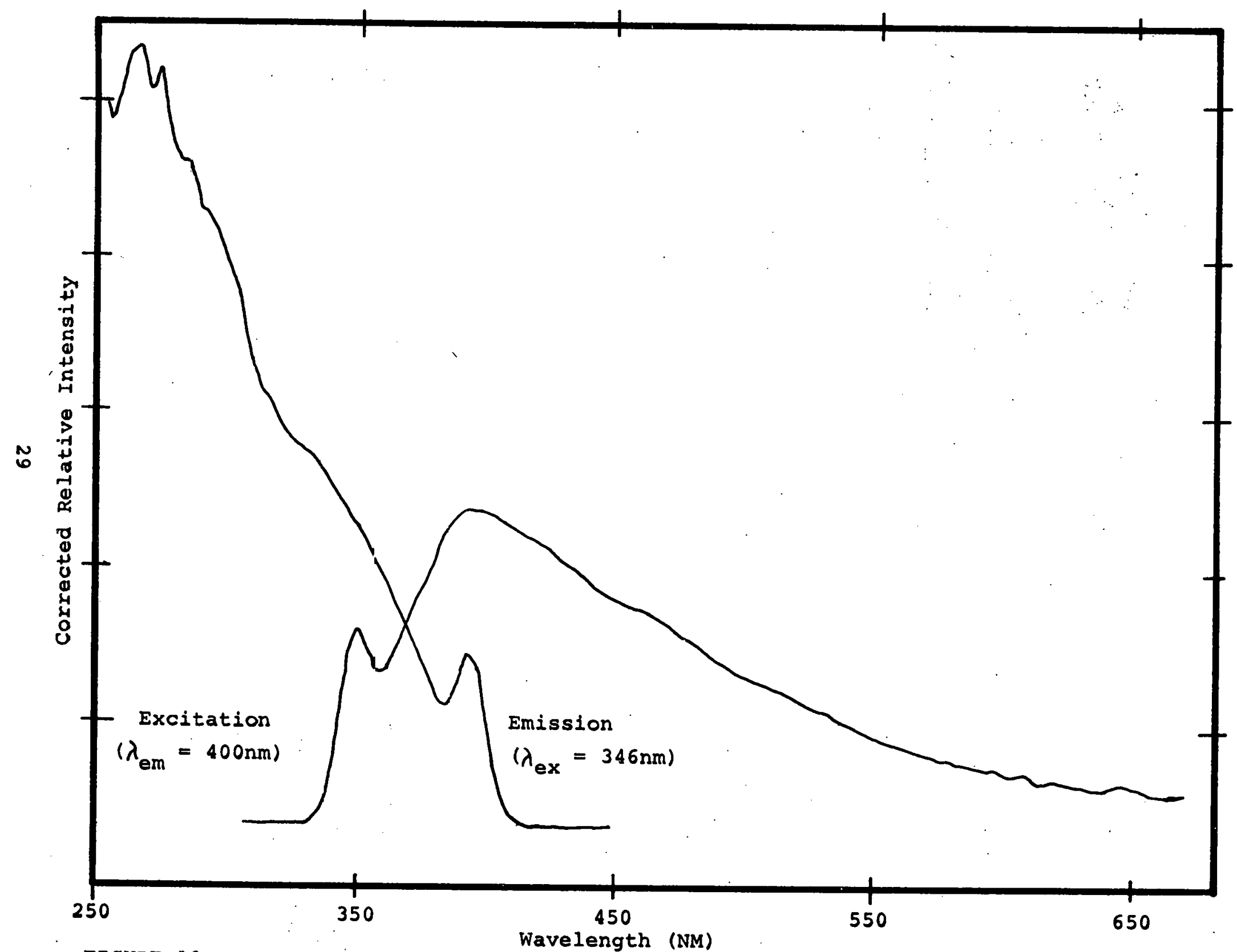

FIGURE 12. CORRECTED IRINCIPAL EXCITATION/EMISSION SPECTRA OF MINAGISH, KUWAIT (10 ppm IN METHYLCYCLOHEXANE) 


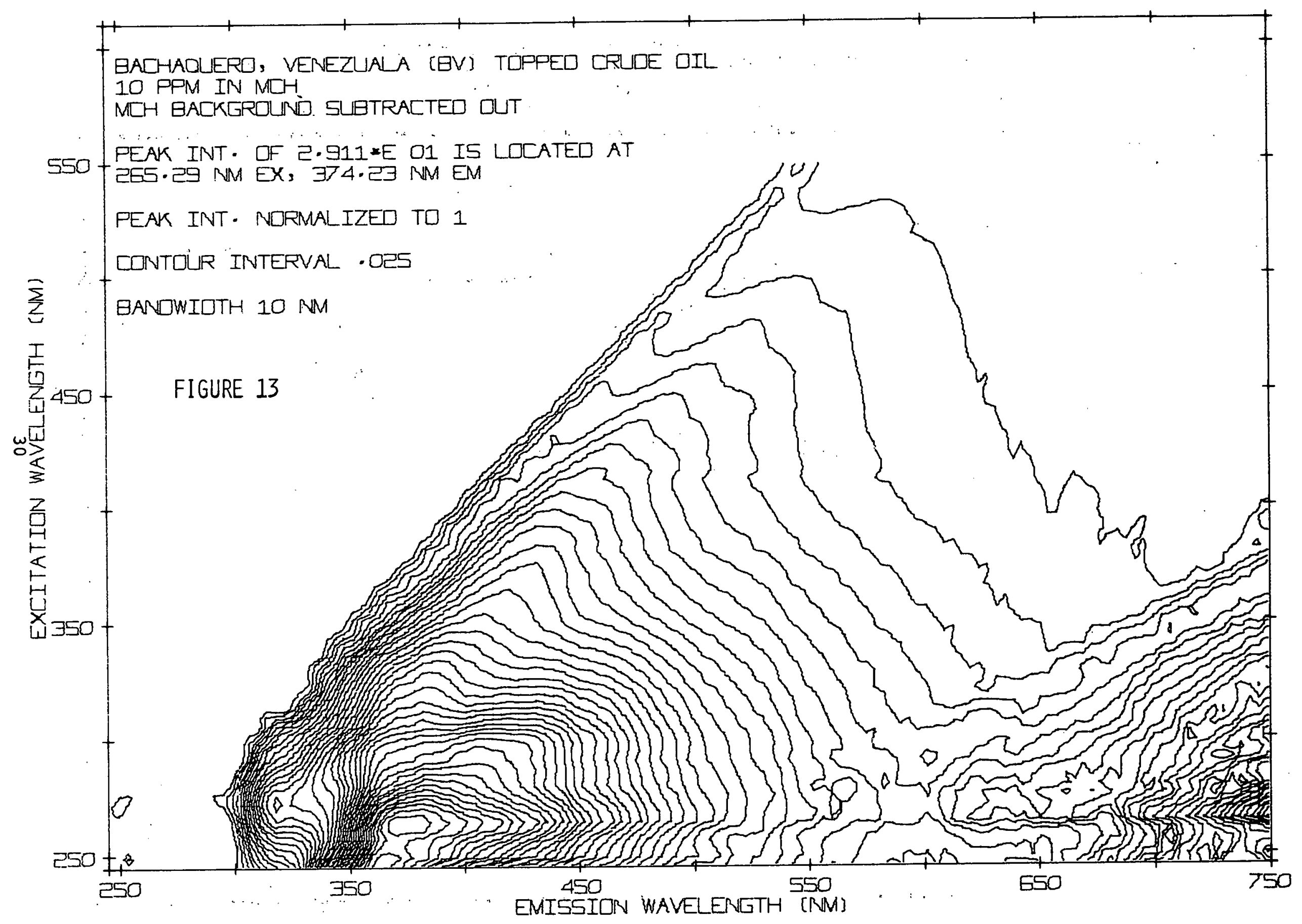




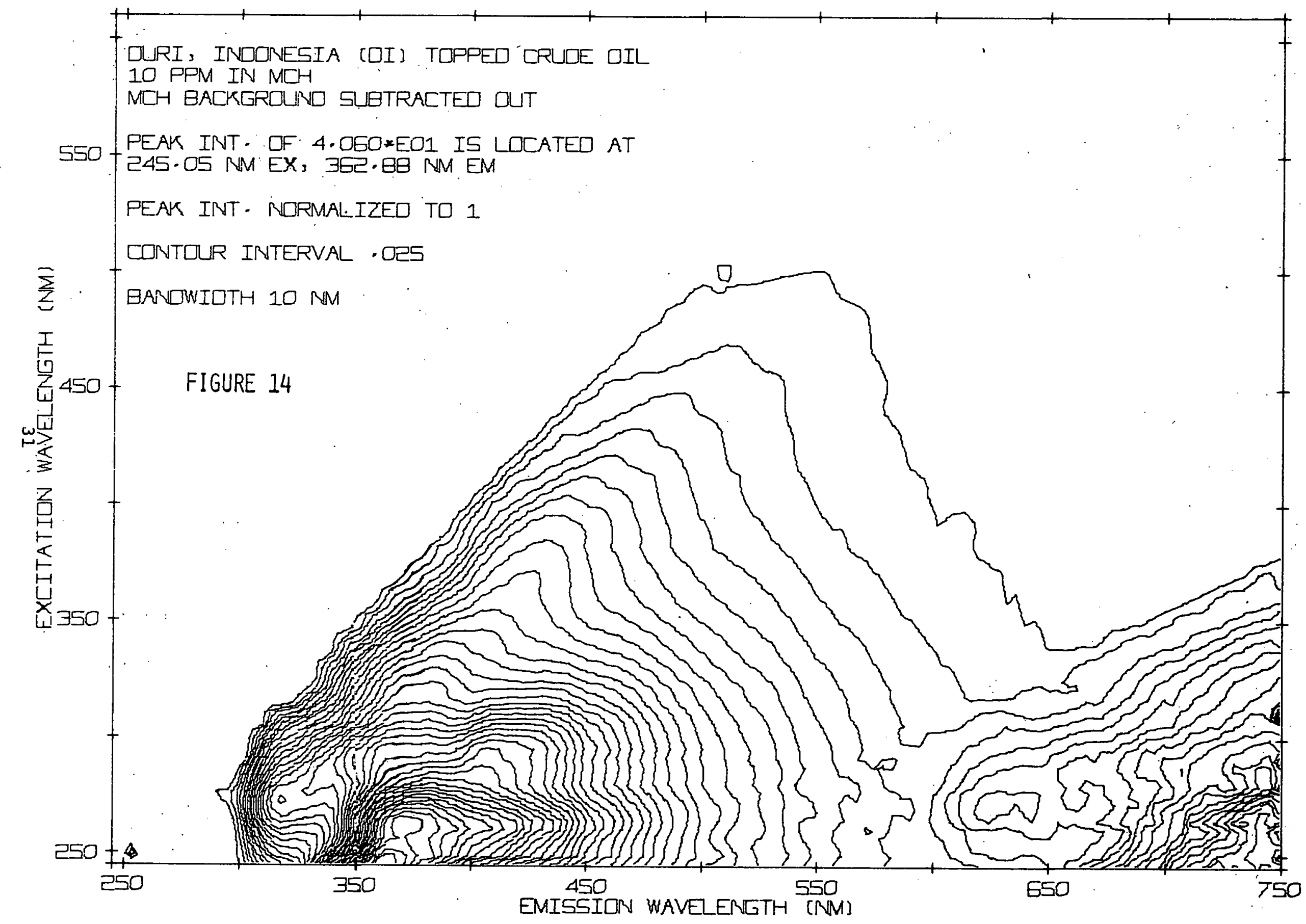




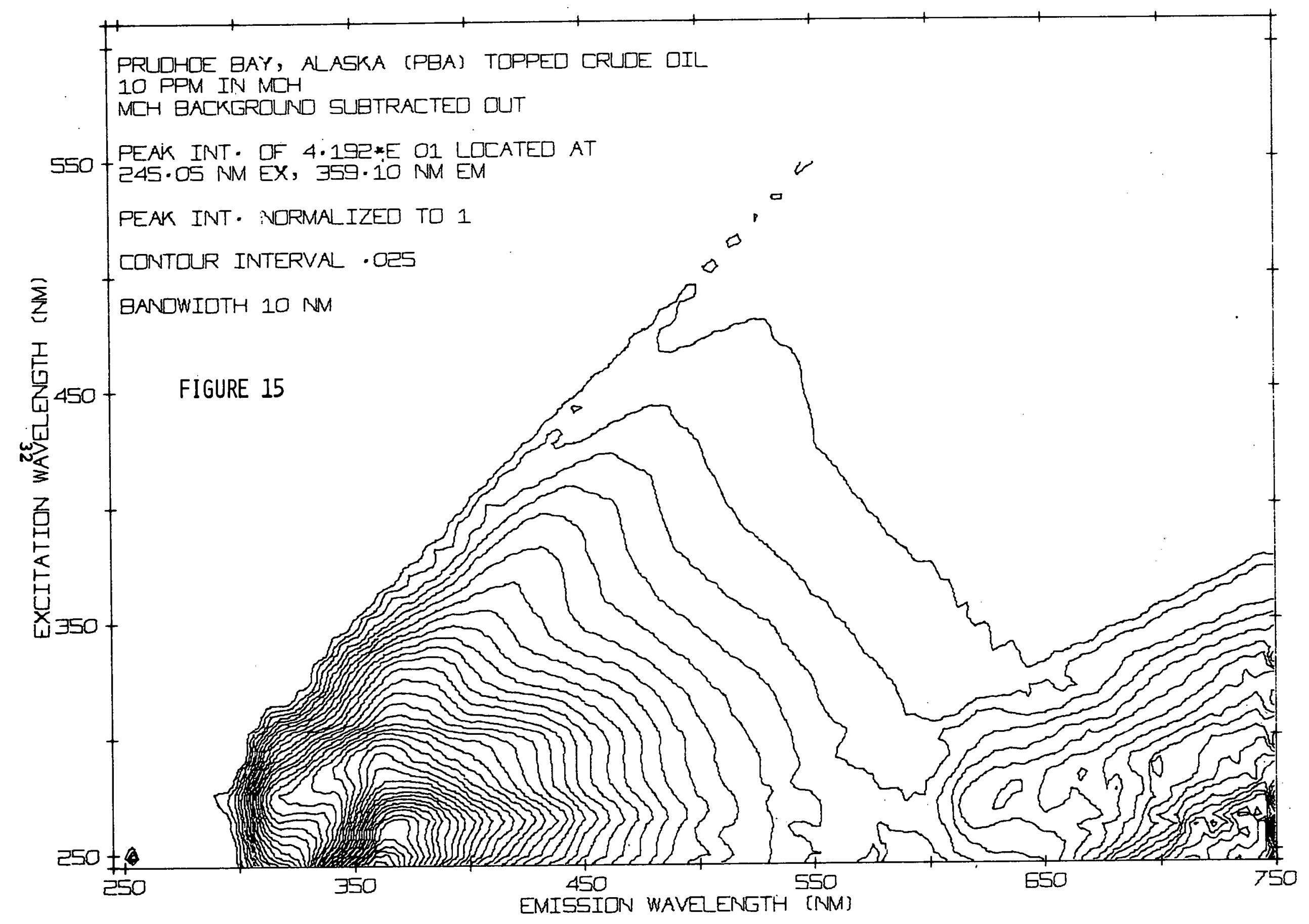




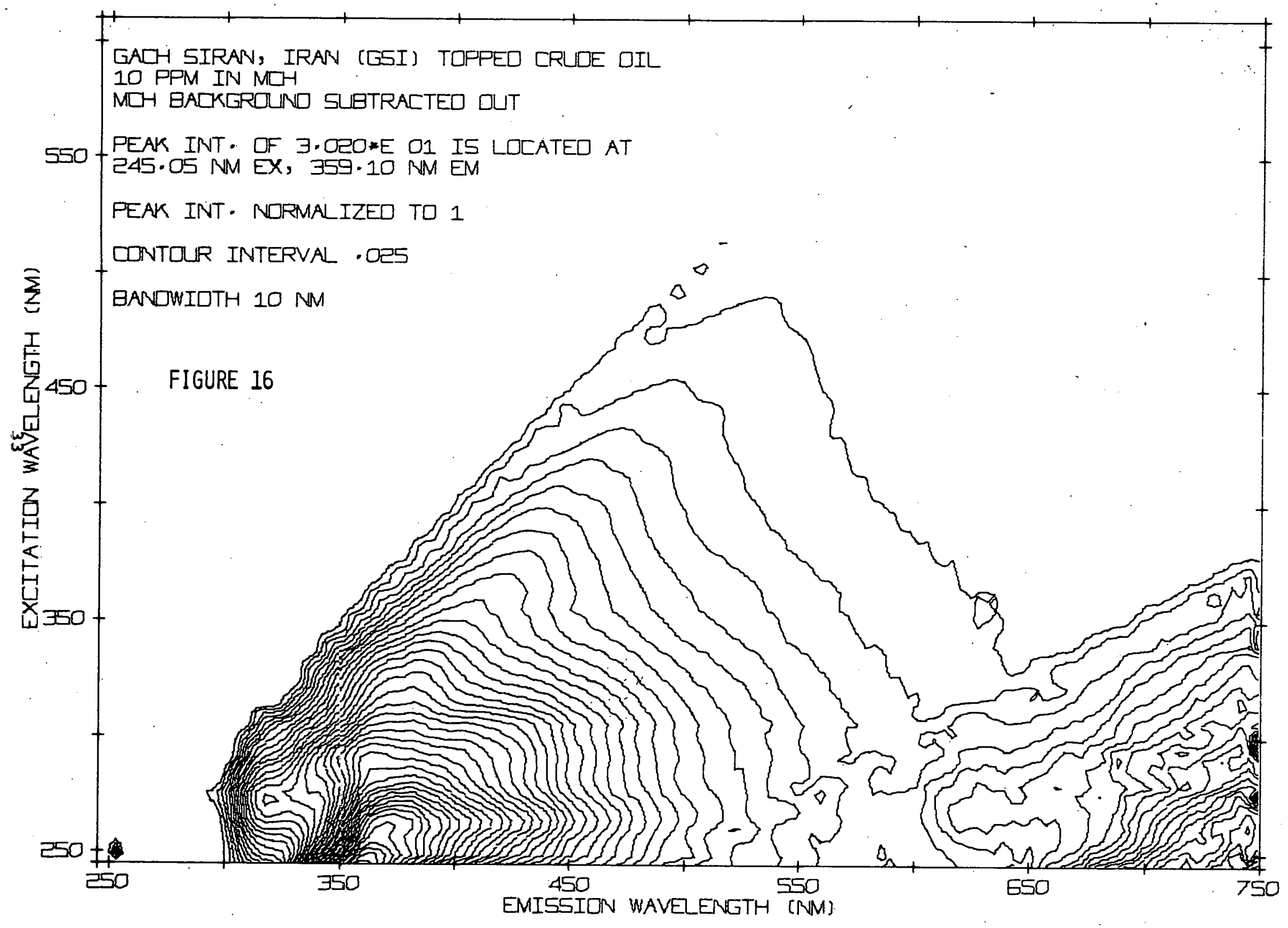




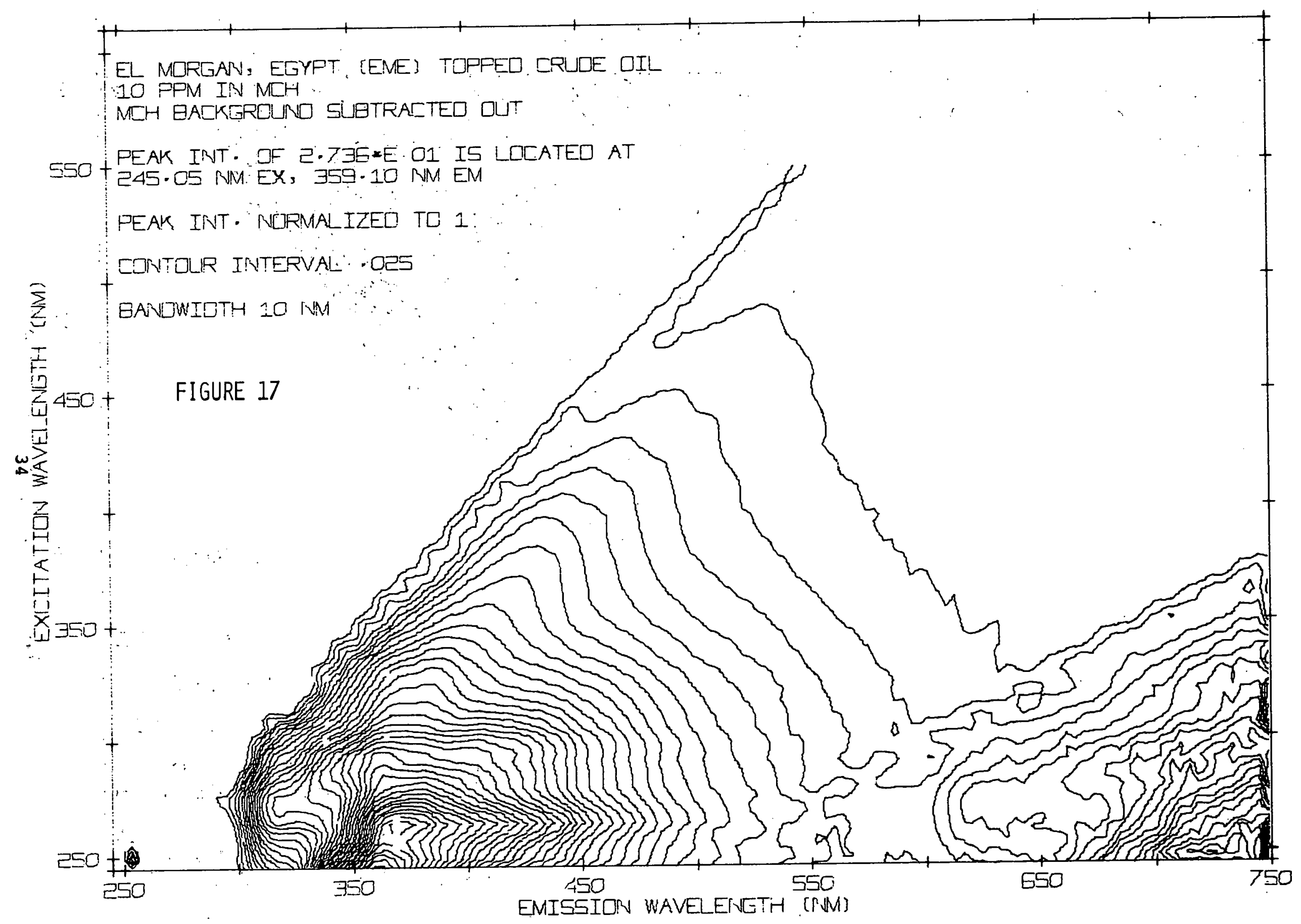




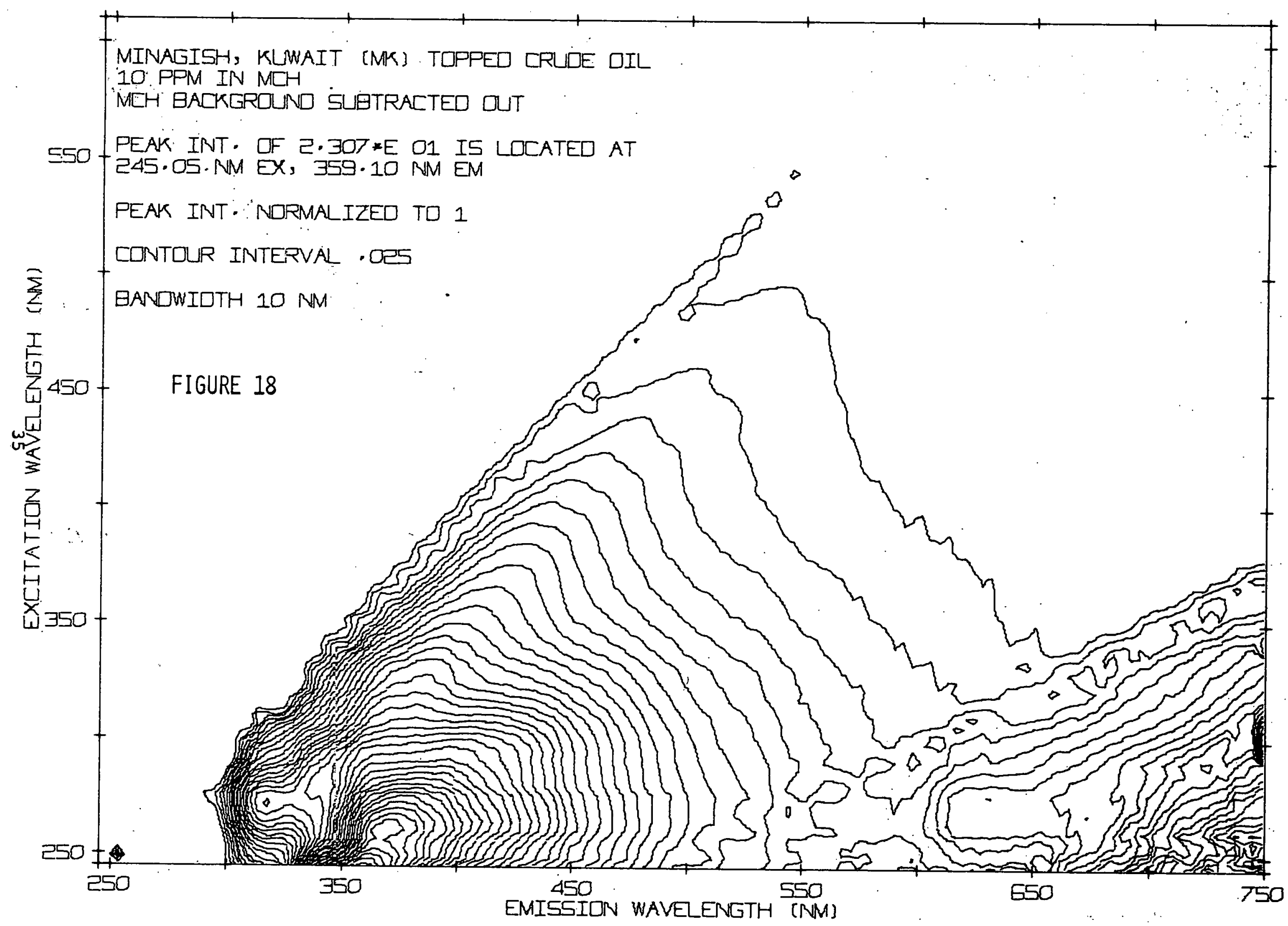




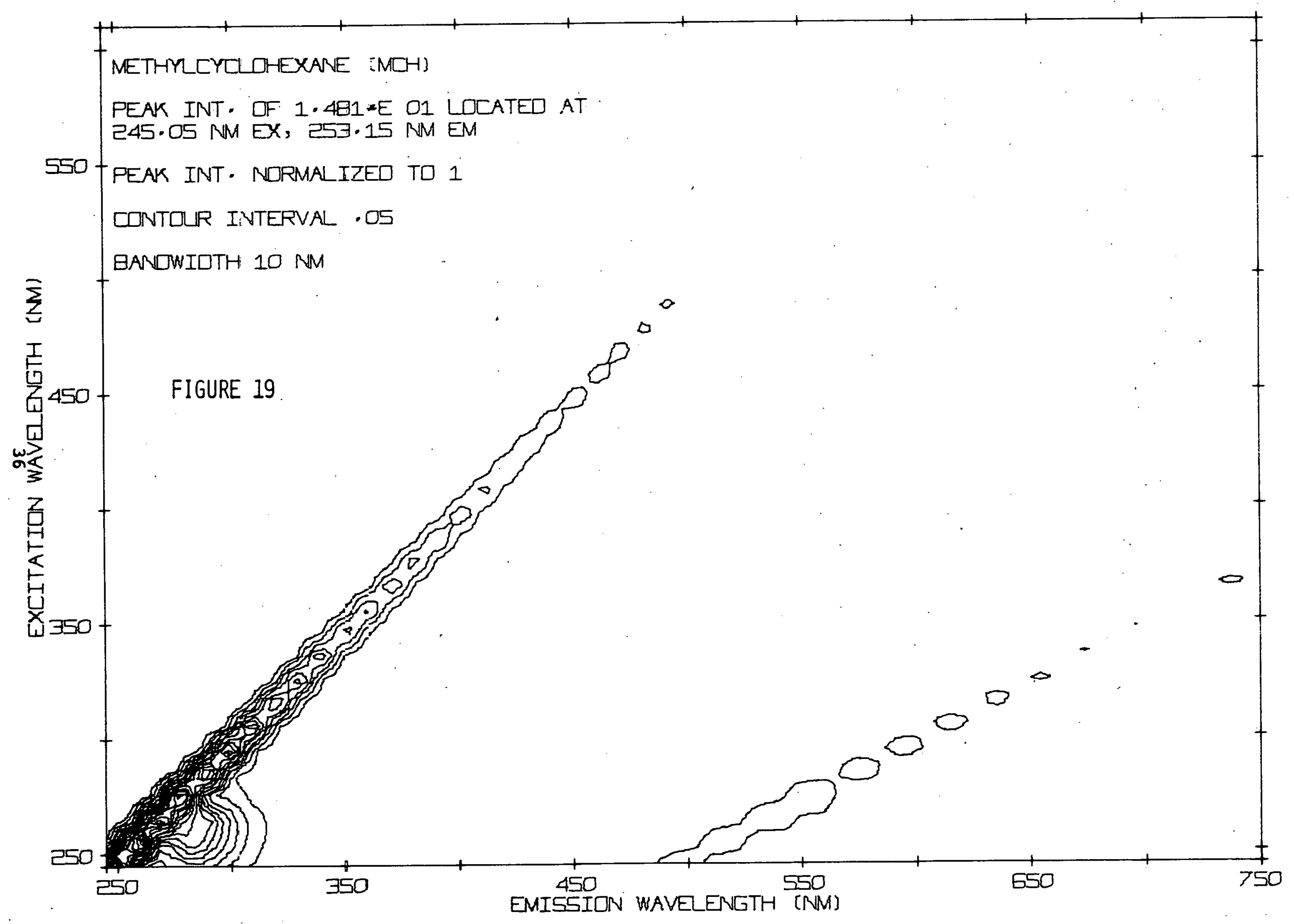




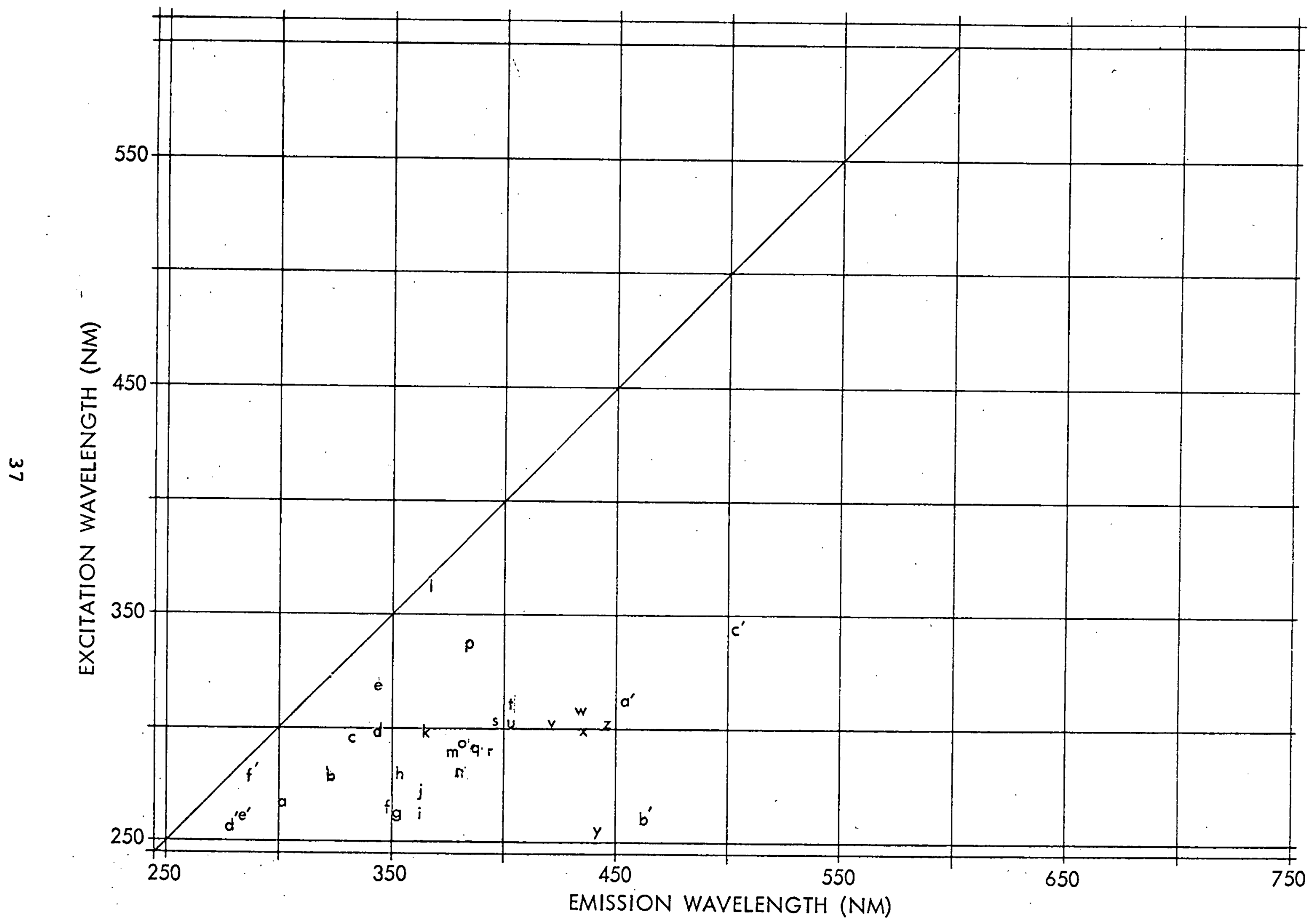

FIGURE 20. UNCORRECTED PRINCIPAI EXCITATION/EMISSION MAXIMA OF MODEL COMPOUNDS 
TABLE 1. UNCORRECTED PRINCIPAL EXCITATION/EMISSION MAXIMA OF MODEL COMPOUNDSA

\begin{tabular}{|c|c|c|c|}
\hline Compound & Excitation & Emission & $\begin{array}{l}\text { Designa- } \\
\text { tion }\end{array}$ \\
\hline Fluorene & 268 & 303 & a \\
\hline Naphthalene & 278 & 324 & $\mathrm{~b}$ \\
\hline 9-Methylcarbazole & 293 & 334 & \\
\hline Carbazole & 293 & $335\}$ & c \\
\hline 2-Methylcarbazole & 297 & 335] & \\
\hline 3-Methylcarbazole & 296 & 342 & d \\
\hline 11-H-Benzo(b) fluorene & 319 & 342 & e \\
\hline 11-H Benzo(a) fluorene & 265 & 347 & $\mathrm{f}$ \\
\hline Triphenylene & 262 & 354 & g \\
\hline $11-\mathrm{H}-\operatorname{Benzo}(\mathrm{a})$ carbazole & 279 & 354 & $\mathrm{~h}$ \\
\hline 7-H-Benzo(c) carbazole & 263 & 362 & $i$ \\
\hline Chrysene & 271 & 363 & j \\
\hline Phenanthrene & 296 & 365 & $\mathrm{k}$ \\
\hline 7-H-Dibenzo $(c, g)$ carbazole & 363 & 367 & 1 \\
\hline Dibenz $(a, c)$ anthracene & 289 & 377 & $\mathrm{~m}$ \\
\hline Picene & 287 & 377 & \\
\hline Anthracene & 260 & 380 & $\mathrm{n}$ \\
\hline 13-H-Dibenzo(a,i) carbazole & 290 & 380 & $\circ$ \\
\hline Pyrene & 337 & 384 & $\mathrm{p}$ \\
\hline Benz (a) anthracene & 290 & 387 & q \\
\hline Benzo (b) chrysene & 289 & 394 & $\mathbf{r}$ \\
\hline Dibenzo $(g, p)$ chrysene & 303 & 395 & \\
\hline Dihenz $(a, h)$ anthracene & 301 & $396\}$ & 3 \\
\hline Naphtho $(1,2,3,4$-def $)$ chrysene & 305 & 397 & \\
\hline Benz (c) acephenanthry lene & 310 & 403 & $t$ \\
\hline Dibenzo $(c, g)$ phenanthrene & 312 & 405 & \\
\hline Benz (a)pyrene & 300 & 405 & $\mathrm{u}$ \\
\hline Benzo(ghi)perylene & 302 & 420 & $\mathrm{v}$ \\
\hline Dibenzo(def mno) chrysene & 308 & 432 & w \\
\hline Benzo (rst) pentaphene & 297 & 434 & $\mathrm{x}$ \\
\hline Perylene & 255 & 440 & $\mathrm{y}$ \\
\hline Coronene & 303 & 446 & z \\
\hline
\end{tabular}


TABLE 1: UNCORRECTED PRINCIPAL EXCITATION/EMISSION MAXIMA OF MODEL COMPOUNDS ${ }^{a}\left(\operatorname{con}{ }^{\prime} t\right)$

$\begin{array}{lccc}\text { Compound } & \text { Excitation } & \text { Emission } & \begin{array}{c}\text { Designa- } \\ \text { tion }\end{array} \\ \begin{array}{l}\text { Dibenzo(b, def) chrysene } \\ \text { Fluoranthene }\end{array} & 312 & 451 & \mathrm{a}^{\prime} \\ \text { Ovalene } & 290 & 463 & \mathrm{~b}^{\prime} \\ \text { Benzene } & 342 & 503 & \mathrm{c}^{\prime} \\ \text { Toluene } & 254 & 278 & \mathrm{~d}^{\prime} \\ \text { Xylene } & 265 & 290 & \mathrm{e}^{\prime} \\ & 275 & 290 & \mathrm{f}^{\prime}\end{array}$

a) Data taken and modified from Table 1 ref, 2 . 


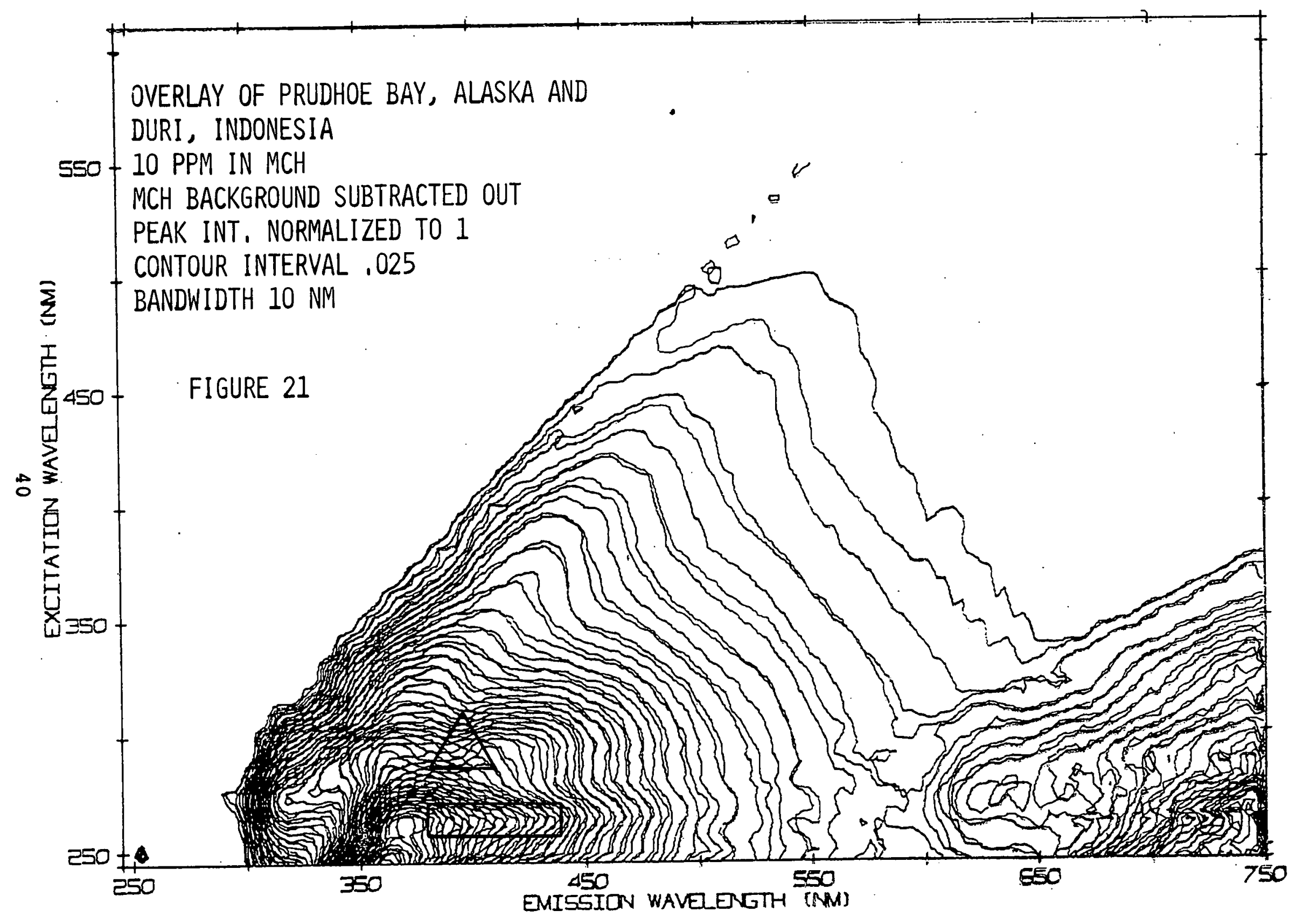




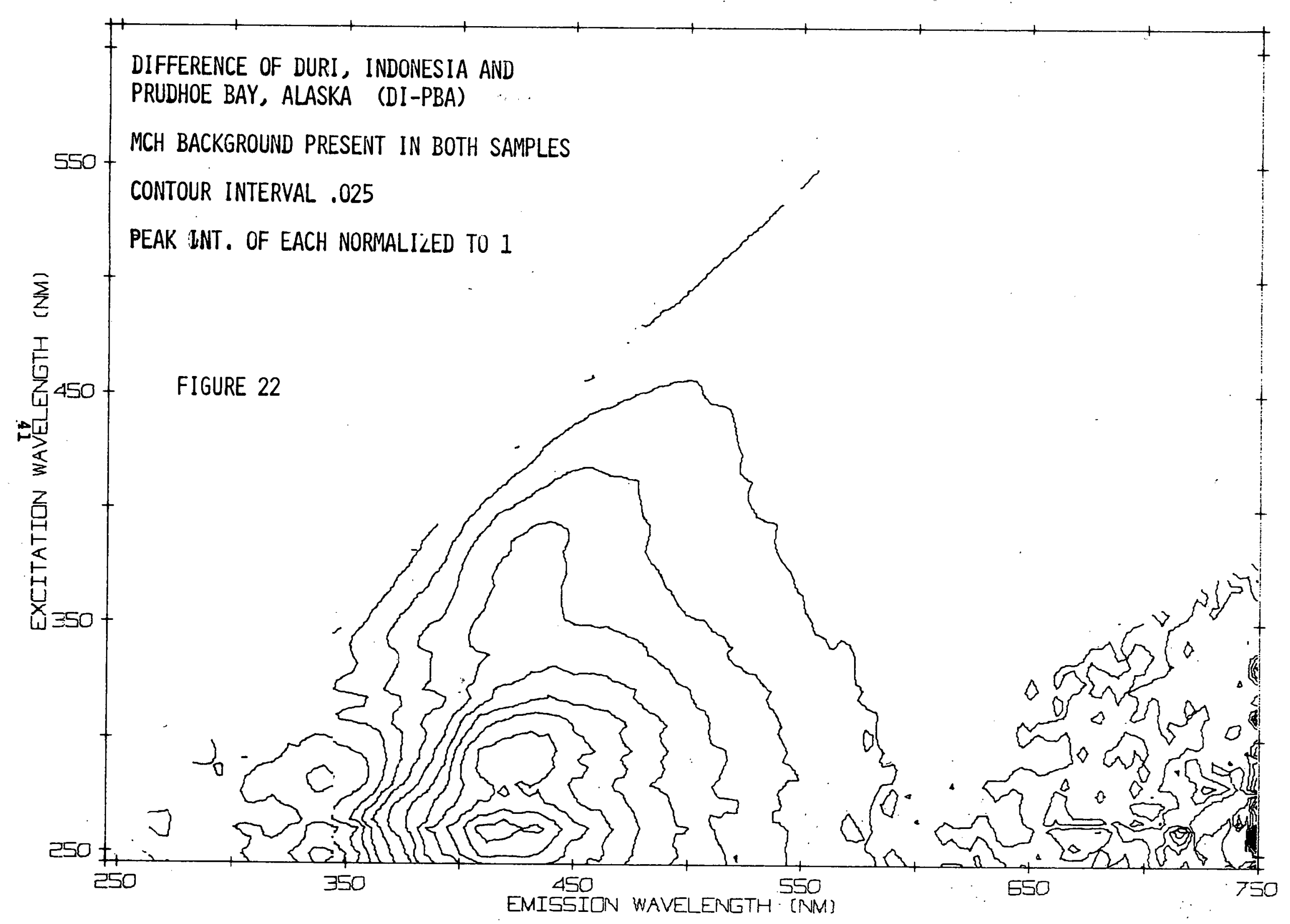




\section{REFERENCES}

1. A. W. Hornig, H. G. Eldering and H. J. Coleman, Pittsburgh Conference on Analytical Chemistry and Applied Spectroscopy 27th, Cleveland, Ohio, Paper 407. (1976).

2. D. M. Jewell, J. H. Weber, H. Plancher, and D. R. Latham, Anal. Chem., 44, 1391 (1972).

3. J. F. McKay and D. R. Latham, Anal. Chem., 44, 2132 (1972).

4. J. F. McKay and D. R. Latham, Anal. Chem., 45, 1050 (1973).

5. C. A. Wilson, E. P. Ferrero, and H. J. Coleman, BuMines RI 8024 (1975).

6. J. T. Brownrigg and A. W. Hornig, Pittsburgh Conference on Analytical Chemistry and Applied Spectroscopy 27 th, Cleveland, Ohio, Paper \#406 (1976). 